\title{
ISABEL COLBRAN: UNA SOPRANO ESPAÑOLA EN EL MUNDO DE GIOACHINO ROSSINI ${ }^{1}$
}

\author{
Marc HeILBRon FerRer
}

\begin{abstract}
The name of the Spanish soprano Isabel Colbran (1784-1845) is linked to Gioachino Rossini. She performed the première of ten of his operas and three cantates and got married to him in 1822. The first part of the article summarizes the highlights of her biography. In the second part, there is a study of her vocality, deepening in the always problematic theme of the classification of her voice. Finally, the article resumes the essential features of her artistic personality, including her compositions. The global objective is to contribute to the study of the theatrical view of the Italian opera in the first half of 19 th Century.
\end{abstract}

\section{Resumen}

El nombre de la soprano española Isabel Colbran (1784-1845) permanece ligado al de Gioachino Rossini de quien estrenó diez óperas y tres cantatas y con el que contrajo matrimonio en 1822. La primera parte de este artículo resume los rasgos esenciales de su biografía. En la segunda, se apuntan las características distintivas de su vocalidad, incidiendo sobre la siempre problemática cuestión de la clasificación vocal de su voz. Finalmente se resumen los rasgos esenciales de su personalidad artística, incluyendo sus composiciones. El objetivo global es hacer una aportación en el terreno del estudio de la práctica teatral de la ópera italiana en la primera mitad del siglo XIX.

En el estrecho margen que la sociedad decimonónica concedió a la mujer en el terreno musical, el caso de las grandes divas operísticas de la primera mitad del siglo XIX, constituye una excepción peculiar que sólo se puede valorar desde una aproximación rigurosa a un fenómeno en el que, con demasiada frecuencia, se han mezclado tópicos y anécdotas que no contribuyen a situar a estas cantantes en el complejo entramado social y artístico que giraba entorno a los teatros de ópera del siglo XIX. Su influencia en el proceso de creación de una ópera iba mucho más allá del que concederíamos a cualquier cantante de nuestro tiempo y su presencia imponía una serie de convenciones ineludibles para el libretista y el compositor. Una de aquellas divas de primer orden, fue la española Isabel Colbran, cuyo nombre permanece asociado al de Gioachino

1. Este artículo resume algunos aspectos de mi tesis doctoral realizada en Bolonia gracias a una beca del Real Colegio de España y dirigida por el profesor Lorenzo Bianconi, catedrático de Drammaturgia musicale de la Universidad de Bolonia. Fue leída en Bolonia el 12 de julio de 1999. Cualquier trabajo de investigación debe gran parte de su éxito a las numerosas personas que con su colaboración han contribuido a llevar adelante el estudio; entre todas ellas, merece particular mención Sergio Ragni, coleccionista e investigador del mundo rossiniano y su entorno, cuyos escritos, consejos y ayuda han resultado esenciales. 


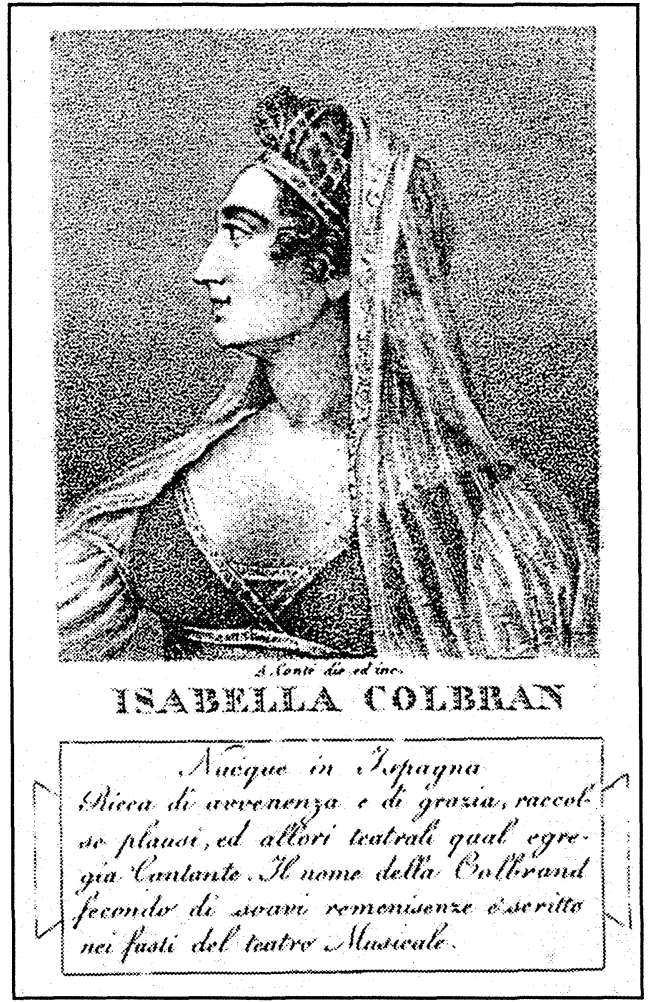

Isabel Colbran.
Rossini, con el que contrajo matrimonio en 1822, y que fue protagonista del estreno de diez óperas rossinianas desde Elisabetta, regina d'Inghilterra (1815) a Semiramide (1823), pero a quien debemos también el estreno de óperas de Giovanni Simone Mayr, Saverio Mercadante, Valentino Fioravanti, Michele Carafa, Francesco Morlacchi, Nicola Manfroce, Manuel García y de otros operistas activos en Italia durante el primer cuarto del siglo XIX.

\section{La vida}

Isabel Baldomera Ángela Colbran Ortolá ${ }^{2}$ era hija de un músico español, Juan Colbran, nacido en Nava del Rey (Valladolid) el 24 de septiembre de 1751 y de Josefa Ortolá, nacida en Almendralejo (Badajoz). Los orígenes de su familia paterna eran muy diversos. El apellido Colbran es de origen anglosajón, aunque sus abuelos y bisabuelos paternos tenían origen francés e italiano, tal como atestigua la partida de bautismo de Juan Colbran:

Grabado de A. Conté, $16 \times 12 \mathrm{~cm}$. Raccolta Piancastelli, I-Foc.

2. La grafía del nombre y los apellidos de la cantante presentan diferentes variantes, dependiendo de las fuentes de consulta y merecen por tanto una aclaración. Según se puede leer en la partida de bautismo el nombre completo de la cantante era "Ysabel Valdomera Angela Colbran Ortola". Es comprensible y lógico - tal como se hace con otros nombres históricos- adecuar el nombre a la grafía moderna y llamarla por tanto "Isabel". No menos comprensible es que en Italia y en otros países sea llamada "Isabella" puesto que este es el nombre que figura en todos los libretos de ópera, y en las cartas que ella misma escribió en italiano, aunque no sería muy lógico que fuese el nombre adoptado en un texto escrito en castellano, puesto que la cantante nació en España, hija de español y escribió su nombre en castellano en los documentos que la vinculan a España como el álbum de canciones dedicado a la reina María Luisa o las cartas dirigidas a Fernando VII para recuperar su pensión. La costumbre de añadir a este primer nombre los otros dos, "Valdomera Angela", debería limitarse a casos en los que se haga referencia a la partida de bautismo, puesto que en las fuentes primarias jamás se hace uso de estos nombres e incluso en el encabezado de la partida de bautismo figura únicamente "Ysabel". En cualquier caso es erróneo el nombre "Ángeles" que aparece en el artículo dedicado a la Colbran de $\mathrm{M}^{\mathrm{a}}$ Encina Cortizo en el Diccionario de la Música Española e Hispanomericana, SGAE, Madrid, 1999. El primer apellido presenta grafías como "Colbran", "Colbrán", "Colbrand". La grafía del apellido más habitual es "Colbran", un apellido de origen sajón procedente de "Kolbrandr". Cfr. Reaney, P. H.: The Origin of English Surnames, London, Routledge \& Kegan Paul, 1967, p. 119. Esta es la forma más correcta, aunque con toda probabilidad el apellido debía pronunciarse acentuado en la España de finales del siglo XVIII. De ahí vendría la costumbre posterior de añadirle la tilde siguiendo las normas ortográficas que se fueron consolidando en el siglo XIX. También el añadido de la "d" (=Colbrand) que el apellido sufrió cuando la cantante viajó a Francia e Italia podría tener su origen en esta pronunciación castellanizada, aunque existe también una versión inglesa con esta grafía. Las tres formas son pues correctas puesto que históricamente las tres variantes tienen su justificación. El autor del artículo prefiere utilizar, sin embargo, la versión sin acento y sin "d" por ser la más utilizada por la cantante y por ser la grafía original del apellido anglosajón, una grafía todavía común en inglés. El segundo apellido debería ser acentuado "Ortolá" puesto que se trata de un apellido de origen mallorquín que actualmente siempre lleva tilde. 
En la Villa de Nava del Rey, a nuebe días del mes de octubre de mil setecientos y cincuenta y un años Yo Don Sebastian Alonso Martín Presbítero Beneficiado y Cura de ella, Baptize e impuse los Santos Oleos segun forma de $\mathrm{N}^{\mathrm{a}}$ Sta. Madre Yglesia Romana a Juan Antonio hijo de Dn Pedro Colbran, Natural de Frans Conte Besanson y $D^{a}$ Isabel Colonia Natural de la Corte Romana su lexítima mujer. Nieto de Ethien Colbran, y de Madalena Mileux naturales de Esamprobans, y de Dn Antonio Patue y $D^{a}$ Angela Colonia; Estos abuelos Maternos aquellos Paternos. Los Maternos naturales de Roma. Fueron sus Padrinos el $\mathrm{H}^{\circ}$ Antonio Alonso, y $\mathrm{D}^{\mathrm{a}}$ Juana Maria Cordona. Nacio el dia veinte quatro de Septembre proximo pasado. Dieronle por Abogada a ${ }^{a}$ Señora de la Merced, testigos Mariano Escarpelino y Joseph Noche, y lo firma =

Dn Sebastian Alonso Martín

Antonio Alonso [palabra ilegible] ${ }^{3}$.

Isabel nació en Madrid el 28 de febrero de 1784, y no el 2 de febrero de 1785 como dicen las notas biográficas de los diccionarios ${ }^{4}$. Tuvo dos hermanas: Josepha, de la que únicamente conocemos la fecha de nacimiento, 12 de julio de $1790^{5}$ y Gaspara, probablemente la mayor de las tres con la que Isabel, desde Italia, mantuvo correspondencia ${ }^{6}$. Nada sabemos de su madre, que pudo morir pocos años después del nacimiento de Isabel ${ }^{7}$. Juan Colbran tocaba el violín y el clarín en la Real Guardia de Corps y a partir de 1793 fue nombrado violinista de la Real Capilla ${ }^{8}$. Fue él quien confió la educación de su hija a Francisco Javier Pareja, violonchelista en la compañía de ópera que actuaba en el teatro de los Caños del Peral, en la que tocaba también Juan Colbran.

Isabel dedicó una canción a su segundo maestro, Marinelli, al que se refiere también Baltasar Saldoni". Este "Marinelli" ha sido comúnmente identificado con el compositor italiano Gaetano Marinelli, que residió en Madrid entre 1786 y 1789. Parece difícil que Gaetano Marinelli fuese su segundo maestro, porque en aquellas fechas Isabel tenía entre dos y cinco años. No parece tampoco muy posible que a tan corta edad saliese de España para estudiar con este compositor. Mucho más probable es que el "Marinelli" al que se refieren las crónicas fuese el castrato Carlo Marinelli, que formaba parte de la compañía del Teatro de los Caños en los años en que Juan Colbran tocaba en la orquesta del teatro y que actuó en este teatro hasta 1793 para ser nom-

3. Archivo Diocesano de Valladolid, Parroquia de Nava del Rey. Libro de bautizados 16 f. 40 . Mi agradecimiento a Agustín Achúcarro por su colaboración en la búsqueda de este documento.

4. El acto de bautismo fue publicado por Pagán, Víctor: "Cosas de palacio: música y monarquía" Scherzo n.86, julio-agosto, Madrid, 1994.

5. Archivo Histórico Diocesano, Madrid, Parroquia de San Martín. Libro Bautizados 47, f. 145.

6. Gaspara realizó gestiones infructuosas para que su padre y su hermana, residentes en Italia, pudiesen recuperar la pensión que tenían de Carlos IV y Maria Luisa de Parma, cuando Fernando VII llegó a España. Gaspara se casó con Josef Pérez, primer tenor de la Real Capilla y su hija, Josefa, contrajo matrimonio con el compositor, crítico y musicógrafo Joaquín Espín y Guillén. Hijos de este matrimonio fueron Joaquín Espín Pérez, también y compositor y Julia Espín, soprano que llegó a cantar la ópera Turanda de Bazzini en la Scala en 1867.

7. Isabel y Juan Colbran salieron por segunda vez de España en 1808 y ya no volvieron nunca más. Resulta extraño que abandonasen a la madre de Isabel y a las dos hermanas en Madrid, manteniendo a la vez buenas relaciones con una de ellas, Gaspara, como demuestra que ésta intercediese a favor de Juan e Isabel ante el rey Fernando VII. Parece más posible que la madre y la hermana pequeña muriesen y que Gaspara, siendo la mayor, se hubiese ya casado en esa fecha con Josef Pérez.

8. Expediente personal de Juan Colbran, Caja 243, Exp. 23. E-Mp.

9. La biografía publicada en el Diccionario biográfico-bibliográfico de Efemérides de Músicos Españoles de Baltasar Saldoni, (Madrid, 1868-1881) reimpresión facsimilar (Madrid, Centro de Documentación Musical, 1986), es una reproducción exacta del artículo publicado por Joaquín Espín y Guillén en la Gaceta de Madrid el 25 de febrero de 1857. 
brado años después maestro privado de la reina ${ }^{10}$. El tercer y último maestro de Isabel, fue el famoso castrato Gerolamo Crescentini con el que Isabel coincidió a la ida, en 1798 o a la vuelta, en 1803 del viaje que éste realizó para encargarse de la dirección artística del teatro São Carlos de Lisboa ${ }^{11}$ :

“il celebre Crescentini ebbe il piacere di formarla nell'arte di canto e, allorché la credette in istato di prendere il suo volo, profettizzò egli la riputazione di cui ella goder dovea un giorno: Io non credo che vi sia in Europa un talento del suo più bello; ed a questo unì egli il dono di tutta la sua musica"'12.

Aquellas lecciones debieron ser decisivas en la formación de la joven cantante, que años más tarde dedicó un álbum de canciones a Crescentini.

La primera aparición pública de Isabel tuvo lugar en septiembre u octubre de 1801, en un concierto ofrecido por Lucien Bonaparte, hermano de Napoleón, que por aquel entonces era el embajador de Francia en Madrid. El motivo fue la celebración de la curación de Carlos IV de una peligrosa enfermedad ${ }^{13}$. Saldoni afirma que Isabel cantó en un concierto ante los reyes y que con ese motivo fue pensionada por la reina María Luisa para estudiar en Francia ${ }^{14}$. Casi no hay documentadas más apariciones públicas de la cantante en España, más allá de algún concierto en casas privadas como el que Isabel Colbran cantó en la "casa vieja" de la Condesa-Duquesa de Benavente en Madrid en 1804, como se puede leer en el artículo publicado en el Memorial literario ${ }^{15}$. Juan Colbran dedicó a la misma Condesa-Duquesa Seis contradanzas, que son la única composición conocida del padre de la cantante ${ }^{16}$. Isabel es también mencionada en la correspondencia entre el tenor Manuel García y la Condesa-Duquesa ${ }^{17}$.

En marzo de 1804, y según se puede deducir de los permisos que solicitó Juan Colbran para ausentarse de la corte, Isabel y su padre partieron hacia Francia ${ }^{18}$. En noviembre de ese mismo año la joven cantante hizo su primera aparición pública en París. Cantó en un concierto

10. Expediente personal de Carlo Marinelli, Archivo Histórico del Palacio Real, Madrid. Caja 71, exp. 3.

11. En Lehuy, A. y Bertini, H.: Encyclopédie Pittoresque de la Musique, París, 1835 , p. 165 se hace referencia a "la prédilection [del compositor Fernando Sor] pour Crescentini, que Sor avait connú à Madrid lorsqu'il donnait des leçons à mademoiselle Colbran"

12. Bertini, Giuseppe: Dizionario storico-critico degli scrittori di musica e de'più celebri artisti di tutte le nazioni si antiche che moderne. Tipografia Reale di Guerra, Palermo, 1814.

13. Esta primera aparición había sido datada en 1799 porque Saldoni hace referencia a que la cantante tenía catorce años cuando participó en el concierto. Sin embargo, Lucien Bonaparte no fue embajador hasta finales de 1800 y los periódicos de la época hacen referencia a una "peligrosa enfermedad" de Carlos IV en septiembre de 1801.

14. El registro de pago de esta pensión figura en el Libro de Concesiones y Gratificaciones de S.M. la Reina. Archivo Histórico del Palacio Real. Registros 785 , f. $107 \mathrm{v}$ y f. 161.

15. Memorial literario, Madrid, 20 de abril de 1805.

16. E-Bbc, M 1453.

17. La correspondecia entre Manuel García y la Condesa-Duquesa de Benavente fue publicada en Solar-Quintes, Nicolas Álvarez: "Manuel García íntimo, un capítulo para su biografía. Anuario Musical, II, CSIC, Barcelona, 1947.

18. Expediente personal de Juan Colbran, Caja 243. Exp. 23. En el diccionario de Saldoni, op. cit. vol. I p. 214, y a partir de él en otras referencias bibliográficas se menciona un viaje de la Colbran a París en 1801, pero éste parece muy improbable y debe ser más bien una confusión, tanto porque este viaje no figura en las solicitudes de permisos de Juan Colbran conservadas en el Palacio Real como porque no hay referencia a ninguna aparición pública de la Colbran en los periódicos franceses de aquella época. 
en la Maison Desmarets, acompañada del cantante Lambert, del pianista Wolff, y de los famosos Philippe Libon, violinista y Rodolphe Kreutzer, que dirigió a la orquesta. La interpretación de Isabel de tres arias de Zingarelli, Crescentini y Portogallo, mereció la atención de diversos periódicos franceses, de dos españoles ${ }^{19}$ e incluso del corresponsal del Allgemeine Musikalische Zeitung que elogió la expresión, el dominio de la voz y la entonación de la cantante ${ }^{20}$. El panegírico del Memorial literario de Madrid no ahorra adjetivos elogiosos:

Doña Isabel Colbran es discípula de los mejores maestros de la Italia, y principalmente de Crescentini, cuya excelente escuela posee con la mayor perfección, y al mismo tiempo el verdadero acento italiano. Este acento, que en vano las Francesas procuran imitar, tiene muchísima expresión, y da á los sonidos una gracia particular que mas directamente suele encaminarse al corazon que á los oidos. Su presencia, su fisonomia insinuante y tímida la recomienda inmediatamente a los expectadores; pero esta recomendación dura hasta que empieza á cantar. En cantando, ninguna necesita. El órgano de la señora Colbran es tan brillante como sonoro y melodioso. No tratamos de ensalzar a los extrangeros á expensas de nuestros artistas nacionales; pero en todo Paris no hay casi voz ninguna que pueda compararse á la de esta gran cantora, tanto por la qualidad del sonido como por el arte y el método con que sabe manejarla."21

En comparación con la carrera de algunas de sus rivales, Isabel retrasó bastante su debut en una ópera completa. Ese debut no llegó hasta finales de 1808 cuando tenía veinticinco años. En aquella época, y aun teniendo en cuenta que muchas veces la fecha oficial de nacimiento de una cantante no coincide con la real, la primera actuación en un teatro se producía antes. El motivo de este retraso tiene que ver con la pensión que le concedió la reina María Luisa tal como se puede leer en la ya citada crónica del viaje a París que publicó El Memorial Literario:

“como pensionada por S.M. la Reyna de España no se presentará en ningún teatro, pero no habiéndose podido negar á las repetidas instancias de los artistas más distinguidos, como Cherubini, Krutzer (sic), Mehul, Isouard y otros muchos, ha determinado dar un concierto en una sala particular"22.

Los años previos a su debut operístico a finales de 1808, Isabel los empleó en dar a conocer su talento en conciertos en Francia e Italia, adquiriendo una fama más que notable si tenemos en cuenta que no había cantado todavía una ópera completa. Prueba de ello es su nombramiento como académica de la Academia Filarmonica de Bolonia — como lo habían sido Mozart y Rossini- por ser:

19. El Memorial literario de Madrid del 20 de abril de 1805 y el Diario de Barcelona entre el 30 de enero y el 12 de febrero de 1806 publicaron un artículo firmado por J.M. de C. que recoge noticias de diversos periódicos franceses y hace encendidos elogios de la cantante.

20. Allgemeine Musikalische Zeitung, Leipzig, 28 de noviembre de 1804.

21. Memorial literario, Madrid, 20 abril de 1805.

22. Íbidem. 
"un Genio privilegiatissimo, Superando con la Rarità della sua voce, e colla profondità del suoi Lumi ogni altra contemporanea nell'Arte del Canto"23.

En abril de 1807, Isabel llegó a esta ciudad y se alojó en casa del barón Capelletti, encargado de negocios del rey de España, amigo de la Condesa-Duquesa de Benavente, que había actuado como agente negociando unos años antes el contrato de Brigida Giorgi Banti y Ana Morichelli para el Teatro de los Caños del Peral de Madrid ${ }^{24}$. En Bolonia, Isabel cantó tres conciertos: en la Accademia Polinniaca (11 de abril), en casa del general Pully (15 de abril) y en la Gran Sala del Liceo Filarmonico (19 de abril). Es probable que el joven Rossini se encontrara entre las 1.200 personas, que según la crónica de $I l$ Redattore del Reno ${ }^{25}$, llenaron la sala del Liceo Filarmonico. El eco del éxito de aquellos conciertos en Bolonia llegó a España y el Diario de Barcelona publicó la traducción de la crónica de $I l$ redattore del Reno boloñés junto a un soneto, en italiano, dedicado al Príncipe de la $\mathrm{Paz}^{26}$. A finales de ese mismo año, Isabel volvió a París. El 24 de diciembre de 1807 y el 24 de marzo, el 16 de abril y el 18 de mayo de 1808, cantó en cuatro conciertos en esta ciudad. El primero de ellos, en la Salle Favart, y los tres siguientes en el Théâtre Olympique. El de la Salle Favart no debió encontrar una acogida tan favorable ${ }^{27}$ como los del Théâtre Olympique en los que el cronista del Moniteur Universel auguraba un espléndido futuro a la cantante, a la vez que realizaba un juicio de las virtudes y defectos de su estilo de canto:

"Cette cantatrice, qui a de très-beaux moyens, une voix forte, harmonieuse, étendue, peut encore acquérir sous le rapport de l'art; elle peut parvenir à plus de souplesse, de flexibilité, à plus

23. Verbale di seduta, Archivo de la Accademia Filarmonica, Libro $4^{\circ}$ dei verbali, p. 331 . Cfr. Gioachino Rossini: Lettere e documenti, vol.I, a cura di Bruno Cagli e Sergio Ragni, Fondazione Rossini, Pesaro, 1992.

24. Yebes, Condesa de: La condesa-duquesa de Benavente. Una vida en unas cartas. Espasa-Calpe, Madrid, 1955 , p. 108.

25. Il Redattore del Reno, Bolonia, 21 de abril de 1807.

26. Pel merito impareggiabile nel canto della Signora Donna Isabella Colbran, Pensionata al Servizio di Sua Maestà la Regina di Spagna, ed Accademica Filarmonica di Bologna. Sonetto dedicato a S.A.S. il Signor Principe della Pace Grande Ammiraglio.

Qual di canore fabbro agili note

Labbro a noi mosse dall'Ibera riva!

Labbro, che tanto in suo concento puote,

Ricco dei doni dell'Armoniosa Diva!

Al peregrino suon, che Italia scuote,

D'onor geloso senso in Lei s'avviva,

Italia, che già all'Ebro in pria le ignore

A lui delizie armoniche nodriva.

Iberia il vede; e ai pregi illustri, e bei,

Onde va altera, del novello vanto

La gloria d'accopiar goden Costei:

E a te, SIGNOR, che al soglio siedi accanto,

Applaude, a te, pel cui favor fra Lei

Tale or sorge la bella arte del canto.

NO.

Diario de Barcelona, 14 de julio de 1807.

Mi agradecimiento a Fernando Sans que me proporcionó el artículo

27. "Diverses circonstances paraissent avoir nui a l'entier développement des moyens de cette cantatrice, et parconséquent au succès qu'elle mérite"La Gazette Nationale ou Le Moniteur Universel, París, 23 de enero de 1808.

28. Gazette Nationale ou Le Moniteur Universel, París, 21 de mayo de 1808. 
de charme dans l'execution; mais ces dons sont malheuresement le partage des voix qui s'affaiblissent, et Mlle. Colbran ne fait qu'acquérir la plénitude de ses moyens" ${ }^{\text {28. }}$.

Mientras la cantante se encontraba en París, se produjeron en España los trágicos acontecimientos que derivaron en la llegada de José I Bonaparte a España y en la Guerra de Independencia. Isabel Colbran, quizás obligada por las circunstancias, aunque más probablemente decidida a sacar partido de la situación política, estrechó sus relaciones con los intereses bonapartistas. José I, cuando todavía estaba en Bayona, la nombró cantante de cámara, aunque no consta que haya participado realmente en la vida musical de la corte madrileña del reinado de José $\mathrm{I}^{29}$. Este nombramiento es sólo uno más de los detalles de la carrera de la Colbran que están ligados al bonapartismo: Su primer concierto en Madrid, organizado por Lucien Bonaparte, la elección de París, como primer destino de su carrera, su nombramiento como cantante de cámara de José I Bonaparte, título honorífico que aparece en los libretos de las primeras óperas que cantó en Italia, la dedicatoria a Marie Julie, esposa de José I de un álbum de canciones y la dedicatoria de otro álbum de canciones a Eugenio Beauharnais, virrey en Italia. También lo son la adquisición de una villa en Castenaso, cerca de Bolonia, procedente de las expropiaciones napoleónicas al Real Colegio de España y finalmente su llegada a los escenarios napolitanos, preludiada por dos conciertos privados en los apartamentos de la reina, Carolina Bonaparte, en el Palacio Real de Nápoles, que pueden hacer pensar que Isabel fue contratada para cantar en los Teatros Reales de Nápoles a través de sus contactos políticos. Esta vinculación, que tiene que valorarse en el marco de la necesaria aproximación de los artistas a los círculos de poder (y el poder en aquellos años en Francia, España e Italia no era otro que el bonapartismo) pone de todas formas de manifiesto una relación estrecha entre la cantante y los intereses napoleónicos en Europa. Por ese motivo, no fue muy sincera la cantante, en una carta que dirigió al rey Fernando VII con la intención infructuosa de recuperar la pensión concedida por María Luisa de Parma en la que señala que el motivo por el que empezó a cantar en los teatros fue su deseo de no verse ligada a José $\mathrm{I}^{30}$. Lo que sí que es cierto, es que Isabel, llevando el título de cantante de cámara de S.M. Católica José I Bonaparte, prefirió emprender una carrera de cantante en Italia, antes que volver a España. Fue una decisión artística comprensible, puesto que la fama que había adquirido y los contactos políticos y sociales que había ido tejiendo le abrieron sin dificultad las puertas de los teatros más importantes de Italia.

Dos rasgos definen esta carrera: Isabel Colbran cantó casi exclusivamente ópera seria y siempre lo hizo en grandes teatros: la Scala de Milán, la Fenice de Venecia, el Comunale de Bolonia, el Regio de Turín, el Valle de Roma y los dos Teatros Reales de Nápoles, el Teatro del Fondo y sobre todo, el San Carlo, en el que cantó de 1811 a 1822 . Únicamente se registran dos actua-

29. Robledo Estairé, Luis: "La música en la corte de José I" Anuario Musical n. ${ }^{\circ} 46$ p. 205-243. El nombramiento se encuentra en E-Mp, G.I. Ca. $8 / 2$

30. "Reusamos el aceptar tan pingüe combeniencia por no ser de legítimo Soberano. Quise más bien ponerme en el Teatro, y ganar mi vida, y mantener así mi familia a costo de mis fatigas". Expediente personal de Isabel Colbran. Caja 243. Exp. 22. E-Mp. 
ciones en un teatro de menor rango, el Teatro Grande de Brescia, en el que interpretó en el verano de 1812 Elisabetta d'Inghilterra de Pavesi y Trajano in Dacia de Nicolini.

El debut operístico tuvo lugar finalmente en la Scala el 26 de diciembre de 1808 interpretando el papel de Volunnia en el Coriolano de Nicolini junto al castrato Giovanni Battista Velluti ${ }^{31}$. Su interpretación no convenció demasiado al crítico de $I l$ corriere delle dame:

"Brava nell'arte musicale, ma timida troppo nello spiegarne le bellezze, pare una principiante di canto, mentre niuno dubita che ne sia già maestra" 32

Muy pronto, sin embargo se ganó los más encendidos elogios de ese mismo crítico en las otras dos óperas que cantó en la misma temporada: Ifigenia in Aulide de Federici y Orcamo de Lavigna:

"Se questa Attrice fu disgraziata come moglie di Coriolano, oggi ha rivendicato il suo merito come figlia di Agammenone [...] ella spiega tale maestria di canto, che rapisce ed attira a se li più delicati sensi dell'anima, e gli affetti li più dolci del cuore umano"33.

Prueba del éxito de aquellas primeras óperas fue la publicación por parte de Ricordi en homenaje a la cantante de algunos fragmentos de Coriolano entre ellos, el aria "Cari figli ah non chiedete" ${ }^{34}$. Acabadas estas representaciones, Isabel volvió a Bolonia, aunque esta vez para cantar en el Teatro Comunale, donde el verano de 1809 interpretó Trajano in Dacia de Nicolini y Artemisia de Cimarosa, acompañada del tenor Nicola Tacchinardi, uno de los mejores amigos de Rossini, y nuevamente por Giovanni Battista Velluti. En Bolonia, participó en la fiesta organizada en el Teatro Comunale para conmemorar la onomástica de Napoleón ${ }^{35}$ y en un concierto con Velluti en la Accademia dei Concordi que tuvo lugar el 25 de agosto.

Antes de finalizar ese año, Isabel Colbran debutó en la Fenice de Venecia con Attila de Farinelli (26 de diciembre) a la que siguió un concierto en este mismo teatro junto al tenor Giacomo David, uno de los tenores más famosos de su tiempo y padre de Giovanni David, también tenor, que coincidió con ella en la compañía de los Reales Teatros de Nápoles. El concierto se celebró el 5 de febrero de $1810^{36}$ y en él participó también el violinista Antonio Camerra. La cró-

31. Giovanni Battista Velluti (1780-1861) debutó en 1800 en Forlì. Está considerado el último castrato de fama internacional que triunfó en los escenarios europeos. Rossini escribió para él Aureliano in Palmira (Milán, 1813) y Meyerbeer, 1 crocciato in Egitto (Venecia, 1824). De esta forma, se podría añadir este nombre al de los otros dos castrati que fueron maestros de Isabel Colbran y que la vinculan directamente con un estilo de canto heredero de la más pura tradición belcantista del siglo XVIII.

32. Corriere delle dame, Milán, 31 de diciembre de 1808.

33. Corriere delle dame, Milán, 4 de febrero de 1809.

34. Scena ed Aria = "Cari figli, ah! non chiedete nell'opera il Coriolano del sig Maestro Giuseppe Nicolini, eseguita nel Regio Teatro della Scala dalla celebre signora Isabella Colbrand prima virtuosa di Camera di S.M. Cattolica il Re, D. GIUSEPPE NAPOLEONE, ed Accademica Filarmonica di Bologna. Dedicata alla medesima. Milano preso Gio. Ricordi in contrada S. Margherita, e Fratelli Artaria sotto il coperto de'Figini. Publicada en Milán en 1809. I-Mc.

35. Atti di Prefettura del Dipartimento del Reno. Titolo XVII Spettacoli/Feste Nazionali, 13 agosto 1809. Bas.

36. Aunque la crónica del concierto no se refiere a las obras que Isabel Colbran interpretó en este concierto, en una copia del aria "Per queste amare lacrime" se puede leer "scena ed aria Per queste amare lacrime Del Sig. Marco Portogallo eseguita dalla Sig. Isabella Colbran Nel Teatro della Fenice di Venezia Il Carnevale dell’Anno 1810. I-Fzc A VII 50. 
nica del concierto no escatimó elogios para la cantante ${ }^{37}$. En esta misma temporada veneciana, interpretó I Gauri con música de Carlo Mellara ${ }^{38}$ (28 de febrero de 1810), representación también coronada por el éxito.

En otoño, la Colbran fue protagonista de tres títulos en el Teatro Valle de Roma: La morte di Semiramide de Nasolini (7 de octubre), el estreno absoluto de la ópera Alzira de Nicola Manfroce (10 de octubre) y una escena lírica de Inés de Castro con música de Migliorucci y Portogallo (27 de noviembre). La morte di Semiramide, estrenada en Lisboa en 1801, fue una ópera que Isabel Colbran cantó en repetidas ocasiones, y el aria "Per queste amare lagrime" de esta ópera, una de sus preferidas en los programas de conciertos. Alzira era la primera ópera del compositor Nicola Manfroce, que con diecinueve años alcanzó su primer éxito teatral que tendría su continuación con el estreno de Ecuba (Nápoles, 1812), en un intento de renovación de la ópera seria italiana, a partir de la tragedia francesa. Alzira, basada en la tragedia de Voltaire y ambientada en el Perú español de la época de Felipe II, es la primera ópera de una lista de títulos de tema hispánico que fueron interpretados a lo largo de su carrera por la Colbran. En esta lista tiene que incluirse también la escena de Inés de Castro de Marc'Antonio Portogallo (Marcos António da Fonseca Portugal) y Vincenzo Migliorucci, alumno de Zingarelli, que la Colbran interpretó en la representación a su beneficio del 27 de noviembre de 1810. El grupo se completa con Cimene de Consalvo (Nápoles, 1814), Caritea, regina di Spagna de Farinelli (Nápoles, 1814), Fernando Cortez de Spontini (Nápoles, 1820), Valmiro e Zaida de Sampieri (Nápoles, 1821), así como las dos óperas de Mozart que la Colbran cantó: Le nozze di Figaro (Nápoles, 1814) y Don Giovanni (Nápoles, 1816). Por su parte, Mennone e Zemira, de Mayr (Nápoles, 1817) tiene su fuente literaria en La hija del aire de Calderón de la Barca. Durante esta estancia en Roma, el famoso pintor español José de Madrazo, realizó un retrato en grabado de la cantante.

Acabadas las representaciones en Roma, Isabel tomó el camino de Nápoles. El día 6 de febrero participó en un concierto en los apartamentos de la reina Carolina Bonaparte en el Palacio Real en el que cantaron también otros tres cantantes (Miller, Martinelli y Marzocchi) y la arpista Rega ${ }^{39}$. El 18 de abril los mismos intérpretes, excepto Miller que fue substituido por Margherita Chabrand, participaron en otro concierto organizado con motivo de la celebración del nacimiento del Rey de Roma al que asistió también el rey ${ }^{40}$

Su primera aparición pública en Nápoles tuvo lugar en la ópera Nina o la pazza per amore de Paisiello en el Teatro del Fondo el 11 de mayo de 1811. Las puertas del San Carlo se le abrieron el 15 de agosto cuando interpretó la cantata L'oracolo di Delfo de Raimondi y La vestale de Spontini (8 de septiembre), en la primera representación italiana de esta ópera, que se presentó

37. "Nulla di più soave, né di più elettrizante pel Pubblico quanto quei che furono eseguiti da questa non mai bastamente commendata Artista"Il Quotidano Veneto, Venecia, 6 de febrero de 1810.

38. Carlo Mellara (Parma, 1778- Parma, 1840) discípulo de G. Ghirotti y F. Fortunati inició a componer ópera desde muy joven. En 1804 estrenó La prova indiscreta en Verona y dos años después Il bizzarro capriccio en Venecia. I Gauri había sido estrenada en Brescia dos años antes de la representación que la Colbran cantó en Venecia, aunque Il Quotidiano Veneto del 24 de febrero de 1810 la anunciaba como ópera nueva. Es muy posible que el compositor hubiese realizado cambios en la partitura desde su estreno.

39. Monitore delle Due Sicilie, Nápoles, 8 de febrero de 1811.

40. Monitore delle Due Sicilie, Nápoles, 20 de abril de 1811. 
en Nápoles en el marco de las estrechas relaciones político-culturales de los reyes napolitanos con Francia. Es posible que Isabel hubiese asistido al estreno absoluto de esta obra durante su estancia en París a finales de 1807. Un mes más tarde en una representación a su beneficio, cantó un fragmento de I Gauri de Mellara, que fue presentado en los diarios de Nápoles como "scena lírica de Palmira" "41. A finales de 1811 se abre un paréntesis en la carrera napolina de Isabel Colbran, que el 26 de diciembre de 1811 debutó en el Teatro Regio de Turín con el estreno absoluto de Nitteti de Pavesi a la que siguieron I riti d'Efeso de Farinelli y Gerusalemme Distrutta de Dusik $^{42}$. En la ópera de Pavesi, el cronista del Courier de Turin expresó un juicio elogioso, pero reservado ${ }^{43}$. Los elogios fueron en aumento con las otras dos obras representadas, tanto en $I$ riti di Efeso de Farinelli ${ }^{44}$ como en la Gerusalemme distrutta de Dusik ${ }^{45}$. El verano de 1812 fue protagonista de la temporada del Teatro Grande de Brescia en la que cantó Elisabetta d'Inghilterra de Pavesi y Trajano in Dacia de Nicolini, junto a Adelaide Malanotte, Maddalena Monticelli, Giovanni Celli y Vincenzo Francesco Fracallini ${ }^{46}$.

Acabadas estas representaciones, Isabel y su padre, volvieron a Nápoles, probablemente para cerrar el contrato para la próxima temporada. En otoño de 1812 no hay documentada ninguna actuación suya en Nápoles, pero a finales de ese año la volvemos a encontrar en el Regio de Turín. El éxito de la anterior temporada, se repitió con las dos óperas que cantó en Turín: Castor e Polluce de Federici y Lauso e Lidia de Farinelli. De camino a Nápoles, ciudad en la que

41. Aunque el Monitore delle due Sicilie de Nápoles del 4 de octubre de 1811 cita la obra como "scena lírica de Palmira", la nota publicada por Il Corriere delle dame de Milán del 2 de noviembre de 1811 identifica claramente la obra "nella scena lírica intitolata I Gauli [sic] musica del sig. Mellara". La relación entre los dos títulos se encuentra en el personaje interpretado por la Colbran, Palmide, no Palmira. La escena que interpretó la Colbran es la escena IX del acto II en la que Palmide canta una larga aria acompañada por el coro y en la que aparece una danza de pastores a la que también se refiere la crónica del Monitore delle Due Sicilie

42. Frantisek Josef Dusik (Dusek o Dussek). Nació en Cáslav en 1766 y murió en Zaticin, Carniola, después de 1816. Hermano de Jan Ladislav. Estudió música con su padre al que sustituyó frecuentemente como organista en su ciudad natal. Estando al servicio de la condesa Lützon, llegó a Italia donde fue primer violinista del Teatro de San Benedetto en Venecia. Desde 1786 fue director musical en la Scala. En 1790, después de pasar un tiempo en su tierra natal, fue organista de la catedral de Liubiana y en 1800 director de la ópera de Breslavia. De 1806 a 1816 fue maestro de banda en Venecia. En Italia estrenó diversas óperas como Questa volta la biscia ha beccato il ciarlatano (Venecia, 1805), La feudataria (Milán, 1806), Il fortunato successo (Venecia, 1812), Roma salvata (Venecia, 1816) y Chi vuol troppo veder diventa cieco (Turín, 1820) y el drama sacro Gerusalemme liberata.

43. "M.me Colbrand qui avait été précédée ici per les éloges les plus flatteurs, dont une actrice puisse s'honorer, ceux du célèbre Paisiello, les á justifiés par la manière don elle a rendu le rondeau du dernier acte: à la considérer comme actrice, elle á de la noblesse maintienu sur la scène; come chanteuse, elle ne pourra être jugée qu'au moment où elle aura pris l'habitude d'un théâtre sur le quel elle paraît pour première fois" Courier de Turin, Turín, 26 de diciembre de 1811.

44. "Il serait difficile de décrire l'effet que cette actrice produit dans la dernière scène du second acte. Il n'y a pas un être bien organisé qui ne soit vivement et profondément ému aun moment où elle prononce avec un accent passionné: $m a$ la mia colpa è amore. Un silence profonde règne dans l'assemblée: tous les yeux son attachés sur la belle Aspasie: sa voix seule se fait entendre, pénètre dans les coeurs: mille sensations diverses agitent l'ame des spectateurs" Courier de Turin, Turín, 20 de enero de 1812.

45. "M.lle Colbrand a mis dans le rôle de Marianne la plus grànde expression. Elle a plus encore, peut-être, que dans les rôles precédens, maintenu cette contenance dramatique et cette dignité théâtrale qu'il est si rare de trouver hors de la capitale, nous ne disons plus de l'empire, depuis de Paris, comme l'ancienne Rome, est devenu l'urbs par excellence. Elle a déployé dans le morceau du second acte toutes les graces de son chant. Il est vrai que ces graces sont simples, et qu'elles n'ebloissent pas au premier abord, mais elles connaissent le chemin du coeur, et sont aûres d'y parvenir" Courier de Turin, Turín, 26 de febrero de 1812.

46. La noticia sobre la representación de Trajano in Dacia proviene del libro Il Teatro Grande di Brescia dal 1800 al 1972 a cargo de la Diputación del Teatro Grande, Brescia, 1971 que recoge en su interior una reproducción facsimilar del libro de A.Valentini Musicisti Bresciani ed il Teatro Grande, Tipografia e Libreria Queriniana, Brescia, 1894. p. 130. 


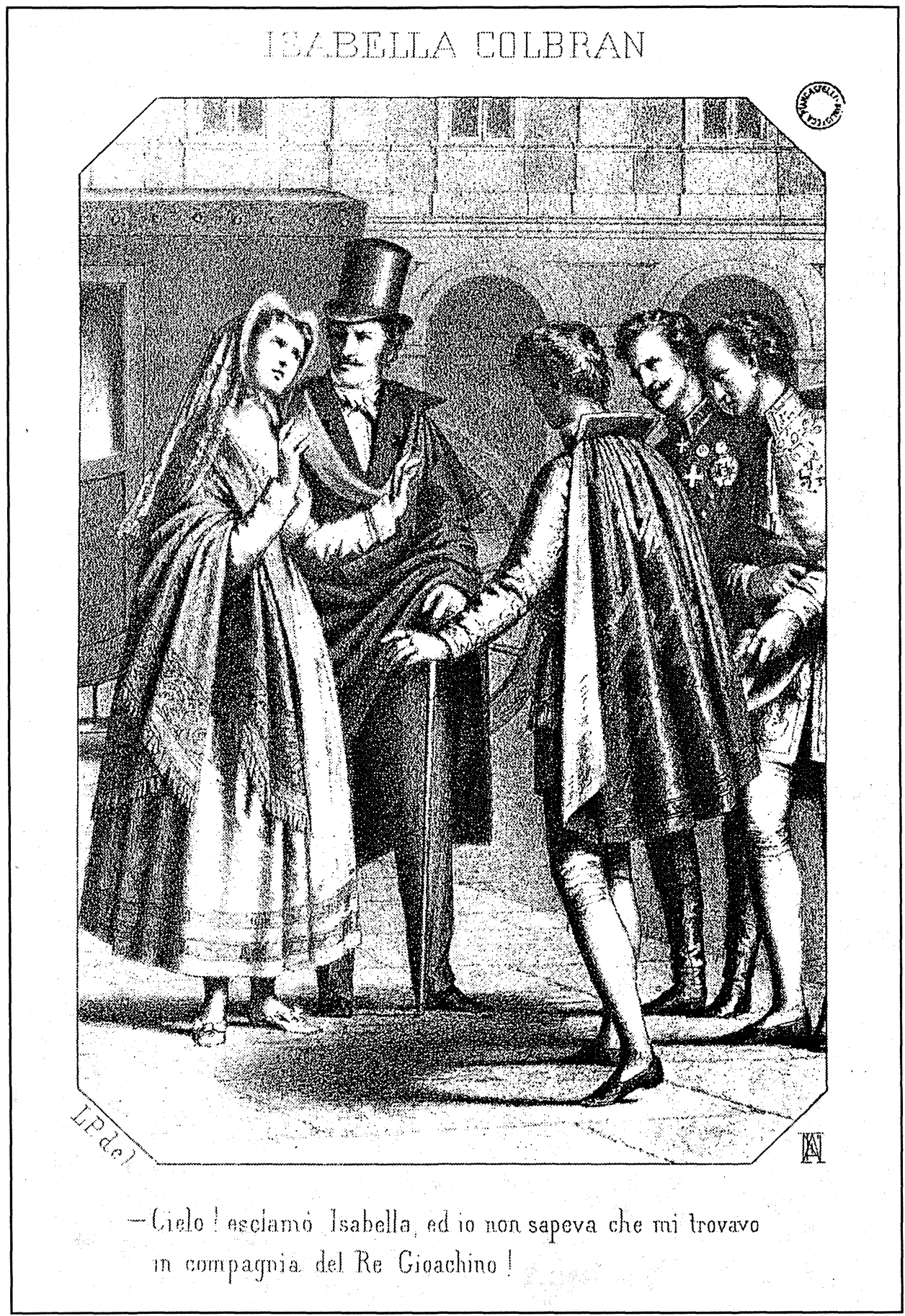

Grabado que representa a Isabel Colbran en Nápoles. Raccolta Piancastelli, I-Foc. 
volvió a aparecer el 18 de abril interpretando Nefté de Fioravanti en el San Carlo, tuvo tiempo de cantar en el estreno de la cantata Deucalione de Francesco Sampieri en el Casinò Lambertini de Bolonia.

La actividad desarrollada en Nápoles por Isabel Colbran ha sido ya muy estudiada ${ }^{47}$. Entre 1813 y 1815, año de la llegada de Rossini a la ciudad, la cantante estrenó, entre otras, la ya mencionada Nefté de Fioravanti, las óperas de Manuel García Il califfo di Bagdad (1813) y La donzella di Raab (1813), así como la cantata Diana ed Endimione compuesta también por el famoso tenor, la Medea in Corinto de Mayr (sin duda, la ópera más importante estrenada por la Colbran aparte de las de Rossini) y otras dos obras de Mayr: la cantata Arianna in Nasso y la ópera Cora. Medea in Corinto fue la primera ópera que el alemán afincado en Italia, Giovanni Simone Mayr, estrenó en Nápoles. Desde 1803, Mayr era el maestro de capilla de Santa Maria Maggiore en Bérgamo, donde tres años después empezó a impartir sus lezioni caritatevoli, de las que fue alumno más distinguido Gaetano Donizetti. Mayr alternaba esta actividad con la composición de óperas, en las que se hace patente la formación germánica del compositor en la inusual densidad de la orquesta. Medea in Corinto está considerada como su obra maestra. El libretista de la ópera fue Felice Romani, famoso después por sus librettos bellinianos y donizettianos. Tres cantantes españoles participaron en la primera representación de esta ópera: Isabel Colbran (Medea), Manuel García (Egeo) y su esposa Joaquina García (Ismene). El personaje clásico de Medea, su concepción patética y violenta, absolutamente central en la obra, se ajusta perfectamente a la personalidad artística de Isabel Colbran. La interpretación de la cantante en el estreno, quedó sin embargo, un tanto deslucida debido a "un'ostinata infreddatura"48.

La llegada de Rossini a Nápoles coincidió cronológicamente con la restauración borbónica. La decisión tomada por Fernando I de reconocer la fidelidad a la institución y no a la persona, abrió la posibilidad a una política de continuidad con las decisiones que había tomado Murat. Esto benefició a Barbaja, el empresario del teatro, y a la Colbran, que se había distinguido por su apoyo a los intereses bonapartistas ${ }^{49}$. El único cambio sustancial, en lo que se refiere a su actividad artística fue su exclusión de la Capilla Real a la que hasta ese momento había pertenecido y de la cual, con el cambio de régimen, fueron excluídas las mujeres ${ }^{50}$.

En los siete años que Rossini pasó en Nápoles, Isabel Colbran estrenó nueve de sus óperas: Elisabetta, regina d'Inghilterra (1815), Otello (1816), Armida (1817) Mosè in Egitto (1818), Ricciardo e Zoraide (1818), Ermione (1819), La Donna del Lago (1819), Maometto II (1820) y Zelmira (1822), todas las que Rossini escribió para Nápoles, exceptuando La gazzetta (1816). Fue también la primera intérprete de tres cantatas: Pel faustissimo giorno natalizio di sua maestà

47. La mayor parte de la documentación puede consultarse en G. Rossini: lettere e documenti, vol.I y II, a cargo de Bruno Cagli y Sergio Ragni. También hay noticias interesantes en Toscano, Tobia R. "Il rimpianto del primato perduto: Dalla Rivoluzione del 1799 alla caduta di Murat" y en Cagli, Bruno “Al gran sole di Rossini” ambos en Il Teatro di San Carlo 17371987, a cargo de Bruno Cagli e A. Ziino, Electa, Napoli, 1989.

48. Monitore delle Due Sicilie, Nápoles, 30 de noviembre 1813.

49. El 7 de mayo de 1813 Il Monitore delle Due Sicilie de Nápoles hacía referencia a las contribuciones realizadas por la compañía del S. Carlo para la guerra. La de la Colbran fue con mucho, la contribución más generosa con 220 liras, que constrastan, por ejemplo, con las 88 que aportó el tenor Manuel García o las 8 del bajo Michele Benedetti.

50. I-As, Casa Reale Ammin. Prot. e Pand. f. 620. 17v. 
il re Ferdinando IV (1816), Le nozze di Teti e Peleo (1816), Omaggio umiliato a sua maestà (1819) y Cantata per la venuta di Francesco I (1819). Interpretó también otras dos óperas de Rossini que no habían sido escritas originalmente para ella: Tancredi (estrenada en Venecia en 1813 y que la Colbran cantó en el Teatro del Fondo en 1816) y La gazza ladra (estrenada en Milán en 1817 y que fue interpretada por Isabel en el Teatro di San Carlo en 1819, 1820 y 1822). De la gran cantidad de óperas que la Colbran estrenó en aquellos años, merecen ser destacadas también la Gabriella di Vergy (1816) y Ifigenia in Tauride (1817), de Michele Carafa, Boadicea (1818), de Morlacchi y L'apoteosi d'Ercole (1819) de Mercadante. Las dos óperas de Carafa fueron dos éxitos importantes en la carrera de la cantante, y durante las primeras décadas del siglo XIX, fueron óperas de repertorio tanto en Italia como en el extranjero. La Boadicea de Francesco Morlacchi supuso un retorno a Italia de uno de los compositores italianos que habían hecho la mayor parte de su carrera en el extranjero. Por último, L'apoteosi d'Ercole fue la primera ópera de Saverio Mercadante, uno de los más prolíficos e influyentes compositores del panorama italiano de su tiempo.

La elección del tema de Elisabetta, regina d'Inghilterra ha sido siempre considerada como un homenaje a la monarquía en el marco del retorno de los Borbones a Nápoles. Y es razonable que así sea, aunque también es posible considerar una intervención directa de la cantante en la elección del título elegido. De hecho, la Colbran había ya cantado una Elisabetta d'Inghilterra de Pavesi en el Teatro Grande di Brescia en 1812, cuyo libreto es atribuido a Giovanni Schmidt, el libretista de la ópera rossiniana. No es descartable pues, que la influencia de la prima donna sobre el empresario y el compositor diese lugar a la elección de este título.

La relación personal entre Gioachino Rossini, Isabel Colbran y Domenico Barbaja exige algunas puntualizaciones. Partiendo de las afirmaciones de Stendhal, tanto en su biografía rossiniana como en su correspondencia, se ha considerado que Rossini inició su relación con la Colbran, después de que ésta hubiese sido amante de Barbaja ${ }^{51}$. Ningún otro testimonio de la época, ni la correspondencia de los tres personajes, apoya claramente esas afirmaciones. Únicamente unas palabras dirigidas por Rossini a Barbaja, podrían hacer pensar que hubiese existido una relación entre el empresario y la cantante, pero las palabras de Rossini no son en absoluto concluyentes $^{52}$. El testimonio de Stendhal no puede ser en absoluto considerado como válido por sí mismo, puesto que las investigaciones filológicas y musicológicas han restado toda credibilidad a su biografía de Rossini, que es un ejercicio literario magistral, aun a costa, muchas veces, de la realidad de los hechos ${ }^{53}$. Desgraciadamente, sin embargo, las consideraciones de

51. Stendhal hace referencia a la relación entre Barbaja y la Colbran en La vie de Rossini, en el cap. XI, Rossini va à Naples y en una carta que escribió a Adolphe de Mareste el 2 de noviembre de 1819, cif. Correspondance, vol. 1 . Editions Gallimard, París, 1968.

52. Una ambigua carta escrita por Rossini y dirigida a Barbaja en la que el compositor dice conocer "quante premure avete per isabela" es el único documento que podría confirmar las aseveraciones de Stendhal. Cagli, B. y Ragni, S.: op. cit. vol. I, doc. 132, p. 278.

53. Los errores, las imprecisiones y las puras invenciones de la biografía de Stendhal están ampliamente documentados en la monografía de Weinstock, Herbert: Rossini: a biography, Knopf, New York, 1968. Sirva simplemente como ejemplo, el testimonio en primera persona de Stendhal sobre el estreno de Elisabetta, regina d'Inghilterra en Nápoles, que describe con todo lujo de detalles en los capítulos XII y XIII de su obra, estreno al que no asistió porque en aquellas fechas se encontraba en Milán como demostró Martineau, Henri: Le calendrier de Stendhal, Le Divan, París, p. 156. 
Stendhal han caído en terreno abonado de la literatura dispuesta a incorporar anécdotas a la leyenda sobre la que se ha construido una imagen completamente distorsionada de algunos compositores del siglo XIX. El caso de Rossini es absolutamente ejemplar en este sentido. Lo único cierto es que en una fecha anterior a 1820, el compositor y la cantante iniciaron una relación que dio origen a su matrimonio en $1822^{54}$. No es descartable, sino al contrario, más bien posible, que hubiese existido una relación entre Barbaja y la cantante, anterior al inicio de su relación con Rossini, pero todas las referencias y anécdotas, sobre esta relación, no tienen ninguna base documental.

El 8 de marzo de 1822, concluidos sus compromisos artísticos en Nápoles, el compositor y la cantante abandonaron la ciudad con destino a Viena, donde iban a ser protagonistas de la temporada de ópera italiana organizada por Barbaja. De camino a la capital austríaca, pararon en Castenaso, donde ella poseía una villa comprada años atrás. En una ceremonia íntima que tuvo lugar en la Iglesia de la Beata Vergine del Pilar de Castenaso ${ }^{55}$, Gioachino Rossini e Isabel Colbran contrajeron matrimonio el 16 de marzo de 1822. A finales de ese mismo mes, llegaron a Viena, donde ella cantó tres óperas en el Hoftheater: Zelmira (13 de abril), Elisabetta, regina d'Inghilterra (30 de mayo) y Ricciardo e Zoraide (5 de julio).

Aunque la decadencia vocal de la Colbran había comenzado ${ }^{56}$, su interpretación de Zelmira todavía estaba a la altura de la reputación y la fama que la precedía:

Mad. Rossini-Colbran, die berühmsteste Sängerin Italiens, hat, in der Augen des Publicums, die große Reputation gerechtfertigt, welche ihr vorangegangen ist. Allerdings lässt sich ein großes Genie auch schon in den einzelnen Sprühungen, welche es in Folge einer momentanen Begeisterung von sich gibt, erkennen. So ist es mit Mad. Rossini-Colbran gegangen: das Publicum hat in dieser oder jenem Theile ihrer Leistung erkannt, was das Totale der Darstellung, gewesen seyn würde, ware die Sängerinn nicht, wie man sagt, durch den Einfluß des Klimas und der höheren Stimmung des hiesigen Orchesters in der absoluten Entwickelung ihre, Talents gestört Worden. ${ }^{57}$

El mismo periódico vienés no ahorró adjetivos elogiosos para describir la presencia escénica y la técnica vocal de la cantante:

Nach der Verwandlung erschein Sgra. Rossini als Zoraide, Figlia d'Ircano, die immer durch imposante Ruhe und edlen Austand hervorragt. Alles was diese Sängerin, mit ihrer Klangreichen, gemüthvolle Stimme und mit der Gediegenheit ihres Vortrag bisher geleistet; schien sie wirklich an diesem Abend noch zu überbieten. Es liegt ein unwiderstehlicher Zauber nicht nur in dieser

54. Las cartas en las que Rossini encargó un monumento para la tumba del padre de la Colbran, fallecido en 1820 , son el primer documento que testimonia la existencia de una relación entre el compositor y la cantante. Cagli, Bruno y Ragni, Sergio: op. cit. vol. I, p. 415-416.

55. La iglesia pertenece al Real Colegio de España en Bolonia. Fue terminada en 1745 y desde esta fecha alberga una imagen de la Virgen del Pilar de 1672, pintada por el boloñés Giambattista Bolognini, que fue un encargo de los colegiales de este Real Colegio.

56. En una carta de Leopoldo de Borbón a su padre Fernando I de Nápoles, el príncipe napolitano informa del éxito de la Zelmira en Viena, aunque se lamenta de que "La Colbran ora M Rossini non abbia più voce" Cagli B. y Ragni, S.: op. cit. vol. II, p. 4.

57. Wiener Zeitschrift für Kunst, Literatur, Theater und Mode, Viena, 2 de mayo de 1822. 
Stimme selbst, sondern auch in der kunstreicher und kunstlos scheinende Verwendung, der des Tones blühenden Reiz ersetzt und den Stoff in frener klarheit entfalten lässt, indem ohne Aufwand und Berechnung, bloß als Product des augenblicklichen Befühls, ihm die zur Natur gewordene Kunst ein überraschend wirksames Gepräge ausdrückt. ${ }^{58}$

Tanto el crítico y musicógrafo Giuseppe Carpani, que asistió a la representación ${ }^{59}$, como el corresponsal en Viena del Allgemeine Musikalische Zeitung fueron también elogiosos con su interpretación, con la que alcanzó, sin lugar a dudas, un gran éxito en Viena. Este último periódico se refiere, sin embargo, a algunos cambios en Elisabetta, regina d'Inghilterra y en Ricciardo e Zoraide destinados a "facilitar" la interpretación de la Colbran que confirman la decadencia vocal de Isabel. El cronista se refiere a tres datos: El primero, la substitución de la cavatina de Elisabetta por el cuarteto "Vedi come esulta", el segundo, la transposición medio tono más grave del aria final de Elisabetta, y el tercero, la reducción a un solo acto de Ricciardo e Zoraide ${ }^{60}$.

De cualquier forma, su decadencia vocal no era todavía tan evidente como para que la acogida de los vieneses no fuese calurosa tanto para Rossini como para su esposa ${ }^{61}$.

Ya de vuelta de la capital austríaca fijaron su residencia en Castenaso. Ante un notario boloñés, firmaron el documento de la dote que ella entregó a Rossini, que arroja luz sobre los grandes beneficios económicos que Rossini obtuvo con este matrimonio ${ }^{62}$.

Rossini trabajó concienzudamente en la que iba a ser la última ópera que escribió para el público italiano y en la última que escribió para Colbran: Semiramide. De la misma forma que la intervención de la Colbran no es descartable en la elección del tema de Elisabetta, regina d'Inghilterra, tampoco lo es en el último título rossiniano que Isabel estrenó, Semiramide, en la Fenice de Venecia el 3 de febrero de 1823. Isabel ya había interpretado en dos ocasiones ese mismo

58. Wiener Zeitschrift für Kunst, Literatur, Theater und Mode, Viena, 16 de julio de 1822

59. Carpani, Giuseppe: Le rossiniane, Minerva, Padova, 1824.

60. La crónica de Elisabetta, regina d'Inghilterra del Allgemeine Musikalische Zeitung de Leipzig fue publicada el 10 de julio de 1822 y la de Ricciardo e Zoraide el 4 de septiembre del mismo año.

61. Una prueba de la excelente acogida en Viena fue la celebración de la onomástica de Isabel, el 8 de julio, después de la representación de Ricciardo e Zoraide en la que Rossini invitó a cenar a los intérpretes de la representación, cena que se vió interrumpida por los gritos desde la calle de un público entusiasmado por la representación, que obligó a los cantantes y al mismo Rossini a cantar desde las ventanas de la casa. Una larga descripción de esta escena fue publicada en el Allgemeine Musikalische Zeitung en la crónica de Ricciardo e Zoraide del 4 de septiembre, esta crónica fue traducida al italiano y publicada por Radiciotti, Giuseppe: op. cit. I, p. 463.

62. El documento, todavía inédito, se halla en I-Bas, Fondo Notarile, Registro 4/7 Notaro Felicori, Angelo, 11 de noviembre de 1822. En él, Isabel Colbran acordó entregar a Rossini 40.000 escudos romanos, una suma muy importante para la época. Tanto es así que el texto redactado por el notario hace referencia a ello: "considerando ancora quantunque sembri generosa l'assegnazione che la Signora Colbran intende di fare al suo sposo per titolo di lei Doti, pare no v'è motivo di opporsi in alcun modo alle sue determinazioni”. Esta cantidad fue pagada en tres partes: en efectivo y con algunos objetos preciosos, en total 13.200 escudos, con la villa en Castenaso y algunas tierras colindantes que fueron valoradas en 14.000 escudos y traspasando el crédito que la Colbran concedió al duque de Alba 12.800 escudos, crédito que había sido garantizado con una casa en Modica (Sicilia). En contrapartida, Rossini se comprometía a abonar mensualmente una pensión a su esposa de 40 escudos. El documento prevé también la cantidad que Rossini debía abonar a la Colbran en caso de separación (1440 escudos anuales). Lo más interesante del documento es quizás que bajo la apariencia de dote, se incluyó en este contrato una forma testamentaria de legado: la mitad de la dote sería para Rossini en caso de fallecimiento de su esposa (como realmente ocurrió) y la otra mitad cedida a la familia de la cantante en caso de que no tuvieran hijos. Aunque jurídicamente se trata de un legado, no se mencionaba como tal en el documento. El motivo de no mencionarlo es sencillo. Un legado testamentario puede ser cambiado en cualquier momento, mientras lo firmado en un contrato no. Esto beneficiaba enormemente los intereses de Rossini, que indudablemente hizo un buen negocio con su matrimonio. 
papel. La primera vez, en Roma en 1810 en La morte di Semiramide de Nasolini y la segunda en 1817 en el San Carlo de Nápoles cuando estrenó la ópera de Mayr, Mennone e Zemira. Rossini trabajó en la composición de Semiramide en otoño de 1822 en la villa de Castenaso, donde se retiraron los recién casados después de la temporada vienesa. El compositor, consciente o inconsciente de que aquella iba a ser la última ópera que estrenaría Isabel, escribió una partitura que pone de relieve las mejores virtudes de la cantante, más ajustada que nunca a sus gustos, y que cierra un capítulo en la producción musical de Rossini.

La temporada en el Teatro La Fenice de Venecia fue bastante accidentada. El título elegido inicialmente para inaugurar la temporada fue Zelmira, la más reciente de las óperas de Rossini, sin embargo, un teatro de la competencia, el San Benedetto, se había adelantado, lo cual había obligado a la dirección de la Fenice a cambiar sus planes a última hora. El 26 de diciembre se representó Maometto II. El público, según el cronista de la Gazzetta Privilegiata de Venezia, acudió a la primera representación "con animo sinistramente preoccupato" por el poco tiempo con el que se había tenido que preparar la representación y porque sabían que la protagonista estaba "parzialmente incomodata da una fierissima costipazione"63. Fuese por enfermedad o porque su voz estaba cada vez más deteriorada, el fracaso de aquella representación fue total. Pocos días después, la ópera tuvo que ser precipitadamente retirada. El público manifestó su desaprobación más allá del propio teatro, con muestras de muy mal gusto: Aparecieron en las paredes de las calles pasquines necrológicos en los que se podía leer "Pregate per l'anima della Colbran Rossini" ${ }^{64}$. Las cosas llegaron a tal punto que el título de la nueva ópera en la que Rossini trabajaba, y que originalmente debía titularse La morte di Semiramide, fue cambiado por Semiramide para evitar nuevos juegos de palabras malintencionados ${ }^{65}$.

El 8 de enero Maometto II fue sustituida por Ricciardo e Zoraide, y las cosas se calmaron un poco y aunque las crónicas periodísticas de la época tienden a atenuar los fracasos, el cronista del periódico veneciano escribió que "la signora Colbran Rossini riscuote seralmente molti applausi" ${ }^{66}$. En cualquier caso, cuando Semiramide se estrenó el ambiente no era el más favorable para la Colbran. La tibia acogida de los primeros días (es significativo que el autor de los artículos de la Gazzetta esperase varios días antes publicar la crónica de la ópera) mejoró y la ópera superó la veintena de representaciones. Aunque la crónica insiste sobre el éxito de las representaciones, algunas expresiones hacen pensar que este éxito no fue tan rotundo como podría parecer ${ }^{67}$.

Acabadas estas representaciones venecianas, volvieron a Castenaso para iniciar los preparativos para su viaje a Londres. Emprendieron el viaje el 20 de octubre. El 9 de noviembre lle-

63. Gazzetta Privilegiata de Venezia, Venecia, 28 de diciembre de 1822.

64. Informe del director general de Policía al Gobernador de las Provincias Vénetas. Cagli, B. e Ragni, S.: op. cit. vol. II, p. 102-103.

65. Carta de Gaetano Rossi a Giacomo Meyerbeer, 26 de julio de 1823 publicada en Meyerbeer, Giacomo: Briefwechsel und Tagebücher, a cargo de Heinz Becker, W. de Cruyter, Berlin, 1960. vol. 1 p. 527-528.

66. Gazzetta Privilegiata de Venezia, Venecia, 13 de enero de 1823.

67. Sorprende, por ejemplo, que la única aria de la Colbran, "Bel raggio lusinghier", una de las más interpretadas hoy del repertorio rossiniano, pasase sólo discretamente, atribuyendo la culpa de ello al coro que acompañaba a la cantante "e quatunque la sig.a Colbran faccia la parte colla nota bravura; pure il Coro chiudendo la Scena, lascia per ultimo un'impressione non del tutto armonica" Gazzetta Privilegiata de Venezia, 22 de febrero de 1823. 
garon a París, permanecieron en la ciudad hasta el 7 de diciembre, y tuvieron tiempo de asistir a representaciones de ópera y a un gran banquete en homenaje al compositor que se celebró el 29 de noviembre y en el que participaron más de cientocincuenta personas ${ }^{68}$. A Londres no llegaron hasta el 13 de diciembre de 1823.

Aunque la presencia de Rossini en la capital inglesa causó verdadero furor, todavía entonces, el cachet de ella superaba al de su marido ${ }^{69}$. En el King's Theatre, Isabel Colbran cantó las últimas representaciones de su carrera: Zelmira en enero y Ricciardo e Zoraide en marzo de 1824, acompañada en ambas por Manuel García. La crónica de The Times del estreno de Zelmira no deja lugar a dudas sobre el estado vocal de la cantante en aquel momento:

a female singer of the first class has become indispensable to the success and estimation of the Italian theatre in London; and if to be found in Europe, the want must be supplied by a management that would deserve patronage. It would be invidious to pursue this remark by an analysis of Madame Colbran's talents; she may have possessed the voice and style suited to a prima donna, but the period has passed, and we can now only recommend that Signor Benelli place her on his retiring pension-list as speedily as possible ${ }^{70}$.

La verdadera triunfadora de aquella temporada fue Giuditta Pasta, llamada a salvar una temporada que inicialmente no había logrado colmar las expectativas del público londinense. La Pasta debutó el 24 de abril con Otello, una de las óperas que Rossini había escrito para su esposa. Sus éxitos continuaron con otros títulos, entre ellos Ricciardo e Zoraide y Semirami$d e$, otras dos óperas estrenadas por la Colbran, lo cual muestra hasta que punto ella no se hallaba ya en condiciones de cantar, cediendo el protagonismo de "sus óperas" a otra cantante. Isabel quedó en un discreto segundo plano, cantando en conciertos privados junto a su marido, y con la intervención, a veces, de otros miembros de la compañía. De alguno de estos conciertos se conserva el programa. En ellos, Isabel Colbran cantaba más números de conjunto que arias como en el concierto que interpretaron el 30 de junio de 1824 en el King's Theatre en el que interpretó el trío Ricciardo e Zoraide y el quinteto de Il turco in Italia. En estos conciertos, la cantante se permitió interpretar piezas de óperas bufas rossinianas, totalmente inéditas en su carrera. Así, por ejemplo, en una nota manuscrita de un programa realizada por el mismo Rossini, la Colbran figura entre los intérpretes del quinteto de La cenerentola o del trío de La Italiana in Algeri.

Una relevancia particular tuvo el concierto del 11 de junio en la Almack's Assembly Rooms, durante el cual se estrenó la única obra de Rossini compuesta en Londres: la cantata $I l$ pianto delle muse in morte di Lord Byron. En la primera parte del concierto ella cantó el dúo de Ricciardo e Zoraide y el dúo de Maometto II, “Anna, tu piangi”. En la segunda, se estrenó la can-

68. Esta cena tuvo resonancia en numerosos periódicos, incluso en Italia, como en el Corriere degli Spettacoli italiani, Bolonia, 18 de diciembre de 1823. El comediógrafo y libretista Eugène Scribe estrenó ese mismo año un vodevil titulado Rossini à Paris ou Le Grand Diner.

69. Ebers, John: Seven Years of the King's Theatre, William Harrison Ainsworth, London, 1828, p. 229.

70. The Times, Londres, 26 de enero de 1824. 
tata en la que Rossini interpretó el papel de Apolo acompañado por nueve solistas de la compañía del King'sTheatre, entre los cuales se encontraban la misma Colbran, la Pasta, García, y su hija, Maria Malibran.

Los Rossini partieron de Londres el 26 de julio de 1824. Durante cinco años se establecieron en París, ciudad en la que vivían también muchos conocidos de ella: los compositores Luigi Cherubini y Michele Carafa, la cantante Giuditta Pasta, y también algunos españoles como José Melchor Gomis, Fernando Sor y Manuel García. La felicidad del matrimonio, después de la retirada de Isabel de los escenarios, no duró demasiado ${ }^{71}$. Desde su llegada, el compositor se hizo cargo de la dirección del Théâtre Italien y trabajó en la composición de sus últimas óperas: Il viaggio a Reims (1825), Le Siège de Corinthe (1826), Mö̈se et Pharaon (1827), Le Comte Ory (1828) y Guillaume Tell (1829). No debieron ser años fáciles para ella, sumida en una forzosa inactividad. Diversas fuentes señalan su desaforada pasión por el juego, que para cubrir sus deudas la obligó a dar lecciones de canto a espaldas de su marido. De la multitud de reuniones sociales a las que el matrimonio asistió en París, merece destacarse una cena en 1829, poco antes de su partida, en la que participaron el tenor Louis Nourrit, Michele Carafa, Fernando Sor y Dionisio Aguado, Pauline Viardot y Manuel García que "à súplica de la Sra. Colbran, cantó las seguidillas españolas del Calesero, propias de su composición"72.

El 13 de agosto de 1829 los Rossini dejaron París y a primeros de septiembre, llegaron a Bolonia. Pasaron el invierno en la casa que el compositor había adquirido en la Strada Maggiore y el verano en la villa de Castenaso. En septiembre de 1830, Rossini volvió a París aunque esta vez, viajó sin su esposa que se quedó en Bolonia acompañada por el padre de Rossini ${ }^{73}$. Lo que iba a ser un viaje de negocios relativamente breve, se convirtió de facto en una separacion definitiva entre ambos. Mientras ella permanecía en Italia, Rossini viajó desde París a España acompañado por Aguado. Aunque la cantante no volvió a su país, su nombre aparece en la lista de destacadas personalidades de la vida musical española que fueron nombrados en 1831 "adictos facultativos" del recién creado Real Conservatorio de Música de María Cristina en Madrid ${ }^{74}$. En las fuentes documentales de este período no faltan algunas escenas de diversión ${ }^{75}$, pero los últimos años de la vida de Isabel fueron, en conjunto, bastante tristes. Una carta escrita a uno de sus amigos, retrata bastante bien la situación:

71. El artículo de Sergio Ragni "Isabella Colbran: Appunti per una biografia", Bolletino Centro Rossiniano di Studi, Pesaro, 1998 incide particularmente en la vida privada de Isabel después de dejar los escenarios.

72. Correo literario y mercantil de Madrid, 14 de octubre de 1829.

73. Las relaciones entre la Colbran y su suegro no fueron fáciles. La correspondencia que éste envió a su hijo son una fuente de información sobre la vida de Isabel en Castenaso. Algunas de estas cartas están publicadas en Jarro (G.Piccini): Giovacchino Rossini e la sua famiglia. Notizie aneddotiche tolte da documenti inediti. R. Bemporad \& Figlio, Firenze, 1902.

74. Cartas Españolas, Madrid, 5-11 de mayo de 1831. En la lista de "adictos facultativos" y "maestros honorarios" del Conservatorio de Madrid, figuran también el tenor Manuel García, su hija, María Malibran y Lorenza Correa.

75. Una carta del padre de Rossini a su hijo escrita el 12 de noviembre de 1830 da noticia de dos conciertos organizados por la Colbran en su villa de Castenaso los días 2 y 9 de noviembre. En la primera, además de la Colbran, cantaron la Viganò, el tenor Foresto y Girolama Dardanelli, la Matilde del estreno de Elisabetta, regina d'Inghilterra. En la segunda cantaron la De Antoni, el tenor Torri y un trío compuesto por Cristini (pianoforte), Centroni (oboe) y Zobboli (fagot). 
Caro Amico,

Quando la fortuna vi è contraria, tutto congiura contro di voi, io ho bisogno d'un amico e la mia mente s'è riportata presso di voi, sapiate che la mia salute è sempre male, che le mie cose vanno di peggio ed io per distrarmi mi sono messa a giocare con una tal disgrazia che non posso prendere una carta che non sia vittima.

L'idea che cambia mi a fatto andare al di là ed essermi imbrogliata, ho un magnifico ritratto a mignatura (un avanzo delle grandezze passate) che a fatto la meraviglia a Parigi, e che a Napoli fatto per Mr. Le Comte mi costò 3 mille franchi, a Firenze che ci sono tanti inglesi che fanno raccolta di belle cose non potreste vedere di venderlo? Caro Bartolini credete che la situazione la più orribile la mia, e voi che avete avuto tanta amicizia per me in tutte le circostanze non mi abbandonate, questo no vi può compromettere poichè nessuno può conoscere l'originale e si può dire è ideale; ditemi come debbo far per mandarlo per il corriere. Aspetto un pronto riscontro e piena di riconoscenza sono sempre vostra

Isabella

le dalie anno avuto un fine infelice la pioggia li anno guastate tutte essendo stato molto amalato il giardiniere li lascio in terra e tutto andato a male

Bologna 8 aprile $^{76}$

Rossini volvió a Bolonia en 1836 y pocos meses después, llegó a la ciudad su amante y futura esposa, Olympe Pélissier, a la que el compositor había conocido durante su estancia en París. Todos los biógrafos coinciden en señalar que en 1836 se firmó la separación legal entre ambos, pero el documento de la separación no ha sido encontrado, aunque cabe suponer que las condiciones de separación se atuvieron a lo que previamente habían acordado cuando la cantante entregó a Rossini su dote ${ }^{77}$. Los contactos entre Isabel y su esposo no fueron demasiado frecuentes en aquellos años ${ }^{78}$. Una carta del padre de Rossini a su hijo testimonia también las dificultades, la soledad y la enfermedad de Isabel en aquellos año.

Aun así, todavía en 1843, ella se dejaba ver en algún acontecimiento social ${ }^{79}$. Isabel murió el 6 de octubre de $1845^{80}$. Un mes antes, Rossini tuvo noticia del estado de extrema gravedad de la cantante, a la que según Zanolini, visitó por última vez el 7 de septiembre de 1845:

Rossini entrò nella camera d'Isabella, e con lei da solo a solo intrattenutosi circa mezz'ora, ne uscì colle guance bagnate di lagrime [...] il 7 ottobre gli giunse l'annunzio che Isabella, dopo di

76. I-Foc, Raccolta Piancastelli. Publicada en Appolonia, G.: Le voci di Rossini, Eda, Torino, 1992. pp. 446-47.

77. V. nota 49.

78. Aunque la Colbran aceptó mal la situación de tener que ver a Rossini junto a otra mujer, está documentada una visita de Rossini y Olympe Pélissier a Castenaso mencionada en una carta de Rossini a su amigo Severini Cfr. Radiciotti, Giuseppe: op. cit. vol. II, p. 213. y descrita por uno de los biógrafos del compositor, Zanolini, A.: Biografia di Gioachino Rossini, Zanichelli, Bologna, 1875. p. 79.

79. El 4 de mayo de 1843 está documentada su presencia en una representación de Otello, organizada por Rossini en el Teatro Contavalli con el fin de recoger fondos para el Liceo Musicale, del que había sido nombrado Consulente Perpetuo en 1839. Cfr. Weinstock, Herbert: op. cit, p. 299.

80. Todas las notas biográficas señalan como el día del fallecimiento de Isabel el 7 de octubre de 1845. El día 7 Rossini tuvo noticia de su muerte, pero ella había muerto el "lunedì [6 de octubre] p. p. alle ore dieci e mezzo pomeridiane" como publicó el periódico teatral boloñés Teatri, arti e letteratura el jueves 9 de octubre. La observación ha sido recientemente realizada por Ragni, S.: op. cit. Pesaro, 1998 p. 45. 
avere ripetuto il nome di lui, aveva finito di vivere. Egli ne fu profondamente accorato e, pur facendo buon viso ai conforti di Olimpia, rimase lungo tempo triste e malinconoso ${ }^{81}$.

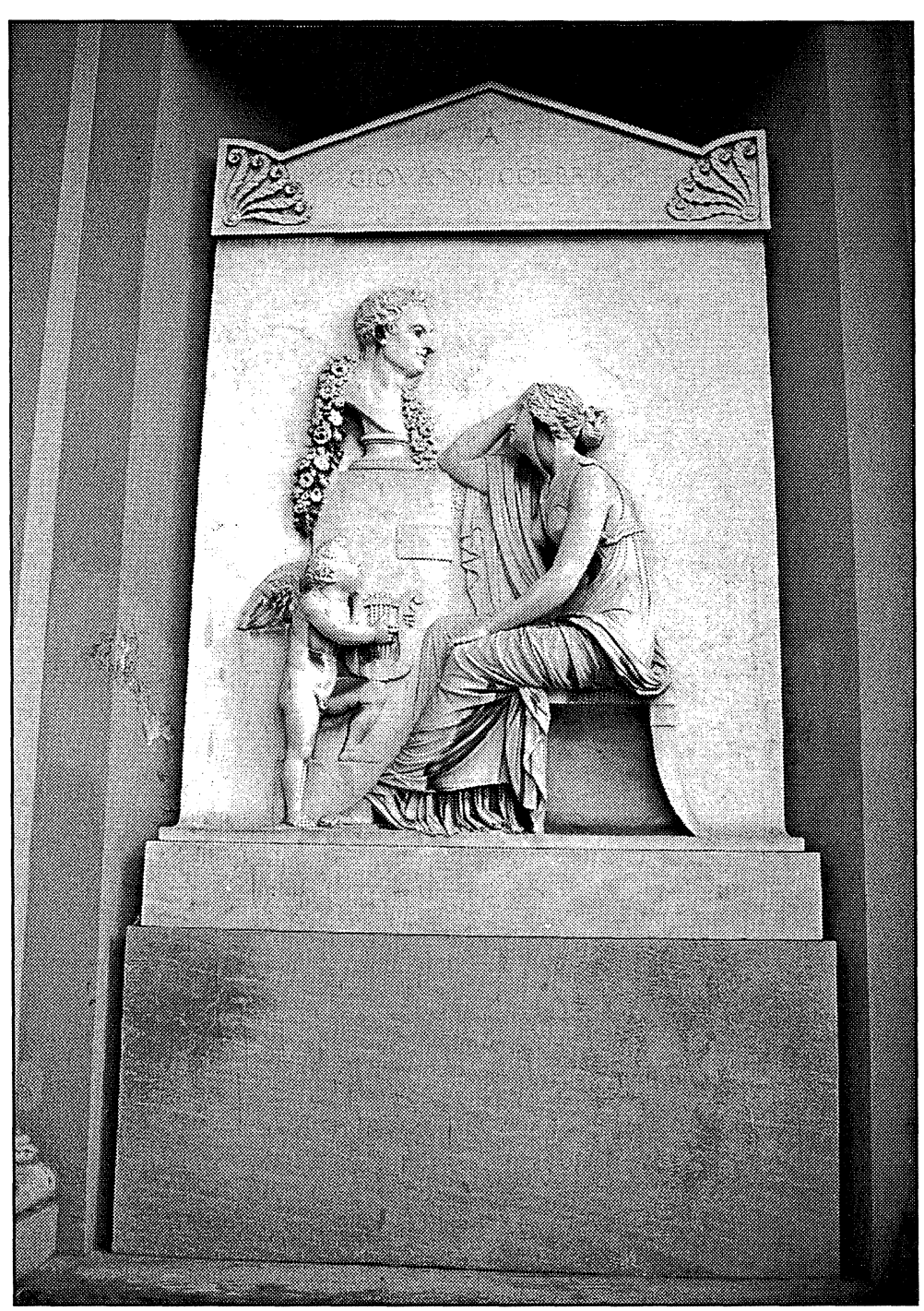

La tumba de Isabel y Juan Colbran en la Certosa de Bolonia.

Foto: C. Iborra.

\section{Vocalidad}

Resulta complejo intentar determinar algunos aspectos de la vocalidad de una cantante a la que no hemos podido escuchar. Sin embargo, esta tarea es imprescindible para poder afrontar, con criterios musicológicos coherentes, las pautas interpretativas de la ópera italiana del siglo XIX. Las descripciones de algunos testimonios y las crónicas de los periódicos de la época son, muchas veces, contradictorias entre sí, requieren un esfuerzo de síntesis, ordenación y aclaración que tiene que ser además necesariamente constrastado con los manuscritos y las partituras de las óperas que Isabel Colbran interpretó.

El ejemplo del caso de Isabel Colbran puede ilustrar lo fácil que es errar en el uso de palabras como soprano o mezzosoprano, que a lo largo del tiempo han variado su significado, y lo habitual que sigue siendo en aspectos de vocalidad, la transposición de los criterios actuales a la interpretación de las óperas de principios del siglo XIX. 
El problema sobre la vocalidad de Isabel Colbran empieza por la situación de su voz en la clasificación moderna de voces femeninas que caracteriza a la ópera italiana. Una crónica del Quotidiano Veneto de Venecia referida a la representación de la ópera Attila de Farinelli en el Teatro la Fenice en 1810 define su voz como de "mezzosoprano"82 y doce años más tarde el Allgemeine Musikalische Zeitung, en la crónica de una de sus apariciones en el Hoftheater de Viena, se refiere a ella como "contralto" 83 . Todo ello resultaría anecdótico, si no fuese porque ninguna crónica se refiere a ella como soprano. El término "soprano", en las crónicas de este período, era aplicado exclusivamente al castrato que interpretaba un papel masculino, como es el caso de Giovanni Battista Velluti en el Trajano in Dacia que cantó junto a la Colbran en Bolonia en $1809^{84}$. Este término, por extensión, se aplicó a la cantante, que interpretaba un rol masculino, como ocurrió - para no desviarnos de ejemplos de las crónicas de la época que mencionan a Isabel Colbran- en el caso de Rosa Mariani, primera intérprete del papel de Arsace de la Semiramide de Rossini que es definida en la Gazzetta di Bologna ${ }^{85}$ como primo soprano, mientras la Colbran-Rossini es la prima donna. Sin embargo, el papel de Arsace es considerado uno de los que podríamos considerar emblemáticos de lo que se considera una contralto rossiniana. El término "soprano" no se refería pues a una clasificación vocal, sino a la definición de un personaje desde un punto de vista dramatúrgico (castrato o mujer que interpretaba un rol masculino, independientemente de cual fuese el registro de su voz).

Para definir a la cantante que interpretaba el papel principal, nos tenemos que conformar con términos más vagos como el de prima donna o prima Attrice, que en sí mismos no aclaran si esta prima donna o prima Attrice era una soprano o una mezzosoprano. Evidentemente, sin embargo, el término existía también en la misma acepción que hoy lo utilizamos, referido a la más aguda de las voces femeninas, pero esta acepción no aparecía en las crónicas y quedaba reservada a un ámbito profesional. Se utiliza, en esta acepción, por ejemplo, en los tratados de canto de la época, usados únicamente por profesionales y estudiantes de canto, a los que nos referiremos más adelante. La polisemia del término soprano ha contribuido no poco a crear cierta confusión en la clasificación vocal, no sólo de Isabel Colbran, sino de muchas cantantes de la primera mitad del siglo XIX .

Otro factor fundamental que se olvida con demasiada frecuencia, es que la práctica teatral de la época exigía de los compositores la creación de papeles escritos "a medida" de las características vocales de un cantante, y que cuando un cantante interpretaba roles que no habían sido escritos para él, se reservaba el derecho de realizar todos los cambios oportunos en la partitura hasta conseguir que los papeles se aproximasen a su vocalidad, justo lo contrario de lo que marca la práctica actual de nuestro tiempo, en la que son los cantantes los que se ajustan a las

82. Quotidiano Veneto, Venecia, 27 de diciembre de 1812.

83. "Am meisten schiè am ersten Abende Mad. Rossini-Colbran durch eine kleine Unpässlichkeit in ihrer Kunstleistung gehemmt; obschon ihre Blüthenzeit vorüber ist, so entzückt dennoch ihr voller Contralt und ihr ausdrucksvoller, edler Vortrag."Allgemeine Musikalische Zeitung, Leipzig, 29 de mayo de 1822.

84. "Il Sig. Gio. Battista Velluti Soprano che percorrendo i Principali Teatri si è acquistata una riputazione..." Il redattore del Reno, Bolonia, 8 de agosto de 1809.

85. La gazzetta di Bologna, Bolonia, 15 de octubre de 1822. 
exigencias de determinados roles. Sólo así, mediante los "ajustes" musicales que se hacían a las partes de cada uno de los cantantes, se puede entender cómo éstos eran capaces de interpretar papeles aparentemente incompatibles ${ }^{86}$.

Sin embargo, tenemos formas de conocer las características que los diferentes registros vocales tenían a principios del siglo XIX. Los estudios sobre la vocalidad de la época pueden partir de dos fuentes fundamentales: los testimonios aportados por aquellas personas que escucharon a un cantante y los manuscritos musicales del estreno de las óperas en las que participaron. A estas fuentes principales, se pueden añadir como mínimo otras dos: las ediciones de algunas partituras que están directamente relacionadas con un cantante y los ya mencionados tratados de canto de la época que son una fuente esencial para conocer la práctica del vocal en el siglo XIX.

La revisión de los manuscritos de las óperas que fueron estrenadas por Isabel Colbran permite establecer una extensión de su voz que se sitúa entre el sol2/la2 y el si4/do $5^{87}$. El sol 2 era de todas formas una nota excepcional en su repertorio y generalmente no descendía más allá del la2 o el sib $2^{88}$. El do5 es una nota aguda bastante limitada para una soprano. No se aprecian diferencias fundamentales entre las primeras y las últimas óperas que estrenó. La comparación de esta extensión con las que ofrecen los tratados de canto de la época puede ser un buen punto de partida para establecer una definición para la voz de la Colbran ${ }^{89}$. Nos hemos limitado aquí a los tratados de la primera mitad del siglo XIX, por ser los más cercanos a la época de la cantante, entre los cuales se encuentra el famoso estudio que escribió Manuel García, hijo, deudor, en parte, de las enseñanzas de su padre ${ }^{90}$.

Partiendo de estos datos, se debe rápidamente excluir una posible clasificación como contralto. Los tratados de Garaudé, Crivelli, Duprez y García señalan como nota más aguda de una contralto el sib4, siempre como nota extrema, rara o débil. Los otros, Mengozzi, Picchianti, Florimo, Lablache y Concone hacen descender las notas más agudas entre el re y el sol4. Lo mismo

86. Uno de tantos ejemplos, siempre en el entorno de la Colbran, podría ser la interpretación de Andrea Nozzari, uno de los tenores que estrenó la mayor parte de las óperas de Rossini en Nápoles, que fue también el intérprete del papel de Don Giovanni en las representaciones de esta ópera mozartiana que la Colbran cantó en Nápoles en 1816.

87. La biblioteca de I-Nc conserva manuscritos de la mayor parte de las óperas que Isabel Colbran estrenó en el San Carlo y en el Teatro del Fondo entre 1811 y 1822 . En I-Mc han sido consultados el manuscrito de Ifigenia in Aulide de Federici, los fragmentos de Coriolano editados por Ricordi y fragmentos de I Gauri de Mellara interpretados por la Colbran en Venecia. En I-Rsc, el manuscrito de Alzira de Manfroce y en I-Bc, uno de los de Medea in Corinto. Las ediciones críticas de las óperas de Rossini editadas por la Fondazione Rossini de Pesaro han sido principal fuente en lo que al repertorio rossiniano se refiere.

88. Una de estas excepciones "D'amor al dolce impero" en Armida de Rossini en la que la Colbran empleó toda la extensión de su voz llegando también al Do5 en la cabaletta del dúo con Rinaldo "Cara, per te quest'anima".

89. Los tratados de canto del siglo XIX han sido estudiados por Marco Beghelli en su tesis doctoral I trattati di canto dell'Ottocento, dirigida por Francesco Degrada y Renato di Benedetto. Università degli Studi di Bologna, 1995. La tesis afronta muchos problemas referidos a conceptos de vocalidad del siglo XIX que tienen una bibliografía científica muy limitada y que han resultado muy útiles para mi estudio.

90. Garaudé, Alexis: Methode complete de chant, Paris, 1826. Crivelli, Domenico: L'arte del canto ossia Corso completo d'insegnamento sulla coltivazione della voce, London, 1847. Duprez, Gilbert-Louis L'art du chant, Paris, 1845. García, Manuel. Traité complet de l'art du chant, Paris, 1847. Mengozzi, Méthode de chant du Conservatoire de Musique, Conservatoire de Musique, Paris, 1804. Picchianti, Luigi: Principi generali e ragionati della musica teorico-prattica. Tipografia della Speranza, Firenze, 1834. Florimo, Francesco: Metodo di canto, Napoli, Girard \& C y Roma, Scip. de Rossi \& C, 1840. Lablache, Luigi. Metodo completo di canto, Milano. s.d. Concone, Joseph: Introduction à l'art de bien chanter, ou Méthode élémentaire du chant..., Paris, Richard, s.d. (hacia 1845). 
ocurre con las notas graves que todos fijan entre el sol2 (nota que Isabel Colbran alcanza sólo en algunas óperas) y notas sensiblemente más profundas que alcanzan el mi2 o el fa2. Según estos tratados, la posibilidad de que fuese una contralto se tiene que excluir completamente, lo cual resta credibilidad a la mencionada crónica del Allgemeine Musikalische Zeitung. Más aun si tenemos en cuenta que en muchas de las óperas que cantó, lo hizo acompañada de verdaderas contraltos (cuyos papeles sí están escritos en clave de contralto) que muchas veces interpretaban el papel de primo uomo como ocurre en las rossinianas La donna del lago (Malcolm, Rosmunda Pisaroni), Maometto II (Calbo, Adelaide Comelli) o Semiramide (Arsace, Rosa Mariani), pero también en óperas anteriores a su encuentro con Rossini como Elisabetta d'Inghilterra de Pavesi (Enrico, Adelaide Malanotte), Alzira de Manfroce (Zamoro, Adelaide Malanotte) o Ninetti de Pavesi (Sammete, Mariana Sessi).

Si continuamos con la extensión que estos tratados presentan para las mezzosopranos, las cosas no resultan tan claras como en el caso precedente. En líneas generales, atribuyen a la mezzosoprano la nota más aguda de la4, todos concuerdan en este punto ${ }^{91}$, excepto Crivelli que señala el sol como la nota más aguda, pero que considera que en casos extremos puede llegar a alcanzar el do5. El mismo Crivelli y también Concone, Duprez y García, consideran que las notas más graves son el sol, el la y el si2, mientras Lablache y Florimo, se conforman con el la2 y el si2.

A partir de estos datos, se pueden afirmar que la Colbran entra en la clasificación de Crivelli, y queda cercana a la de los demás, de lo cual se podría deducir que fue una mezzosoprano en los primeros años de su carrera (justamente en la época en que se escribió la crónica de Il Quotidiano veneto) para pasar después a un registro de soprano.

Queda finalmente repasar las extensiones que los mencionados autores consideran para las sopranos. Aquí las coincidencias son mayores, aunque tampoco perfectas en todos los casos. Por lo menos dos autores coinciden sin ningún problema. Concone y García fijan el la y el si2 como notas más graves mientras el agudo se sitúa en el do5, aunque en el caso de García señala que es posible, aunque raro que llegen al fa5. También puede entrar en la clasificación de Crivelli que sitúa la extensión de la voz de soprano entre el si2 y el do5, añadiendo algunas notas más agudas como raras. La Colbran cantaba roles con algunas notas más graves y alcanza simplemente el do5. Tampoco aquí son muy notables las discrepancias; Mengozzi, Garaudé y Lablache consideran en do5 la nota más aguda, aunque la Colbran cantaba notas por debajo del do3 que ellos señalan como nota más grave.

De todo ello, se podría deducir que las óperas escritas para Isabel Colbran se encuentran entre el registro de mezzosoprano y el de soprano. El problema se puede solucionar haciendo otras consideraciones. No tenemos que olvidarnos que en la época de esta cantante, el término "mezzosoprano" no era aceptado unánimemente como un registro específico de la voz. Prueba de ello es que las partituras de la época, únicamente contemplaban las claves de do de soprano y de contralto, y que los roles escritos para la Colbran están escritos siempre en clave de soprano, lo

91. Algunos eliminan a la mezzosoprano como registro y consideran únicamente a la soprano y a la contralto (Picchianti e Garaude). 
cual es ya muy significativo. No contribuye a clarificar mucho las cosas la confusión que se da en la actualidad entre los términos contralto y mezzosoprano rossinianas, que son utilizados indistintamente sin hacer distinciones entre ellos cuando se refieren a roles como los de Isabella de L'italiana in Algeri, Cenerentola, o Rosina en Il barbiere di Siviglia. Lo que sí que se puede demostrar es que los roles que Rossini creó en estas óperas se mueven en un registro más grave que el habitual de la Colbran. Rossini - siguiendo la práctica teatral tan habitual en su tiempo del autoplagio - utilizó en muchas ocasiones temas musicales en una ópera que ya habían sido utilizados en óperas anteriores. Esto también ocurre en arias que estrenó la Colbran y la comparación entre las diferentes versiones de estas arias puede aclarar algo más sobre el registro de la Colbran. Un ejemplo lo encontramos en la segunda sección del aria di sortita de Elisabetta, Regina d'Inghilterra "Questo core" que Rossini volvió a utilizar en la segunda sección de la famosa aria de Rosina de Il barbiere di Siviglia "Io sono docile", en la cual se aprecia cómo la Colbran (primera intérprete del papel de Elisabetta) canta un tono más agudo que la Righetti Giorgi (primera intérprete del papel de Rosina) y que en el desarrollo del tema la Colbran alcanza una tesitura sensiblemente más aguda que la de la Righetti Giorgi, cantante que ha sido siempre considerada contralto o mezzosoprano.

\section{Ejemplo primero:}

\section{Elisabetta Regina d'Inghilterra}
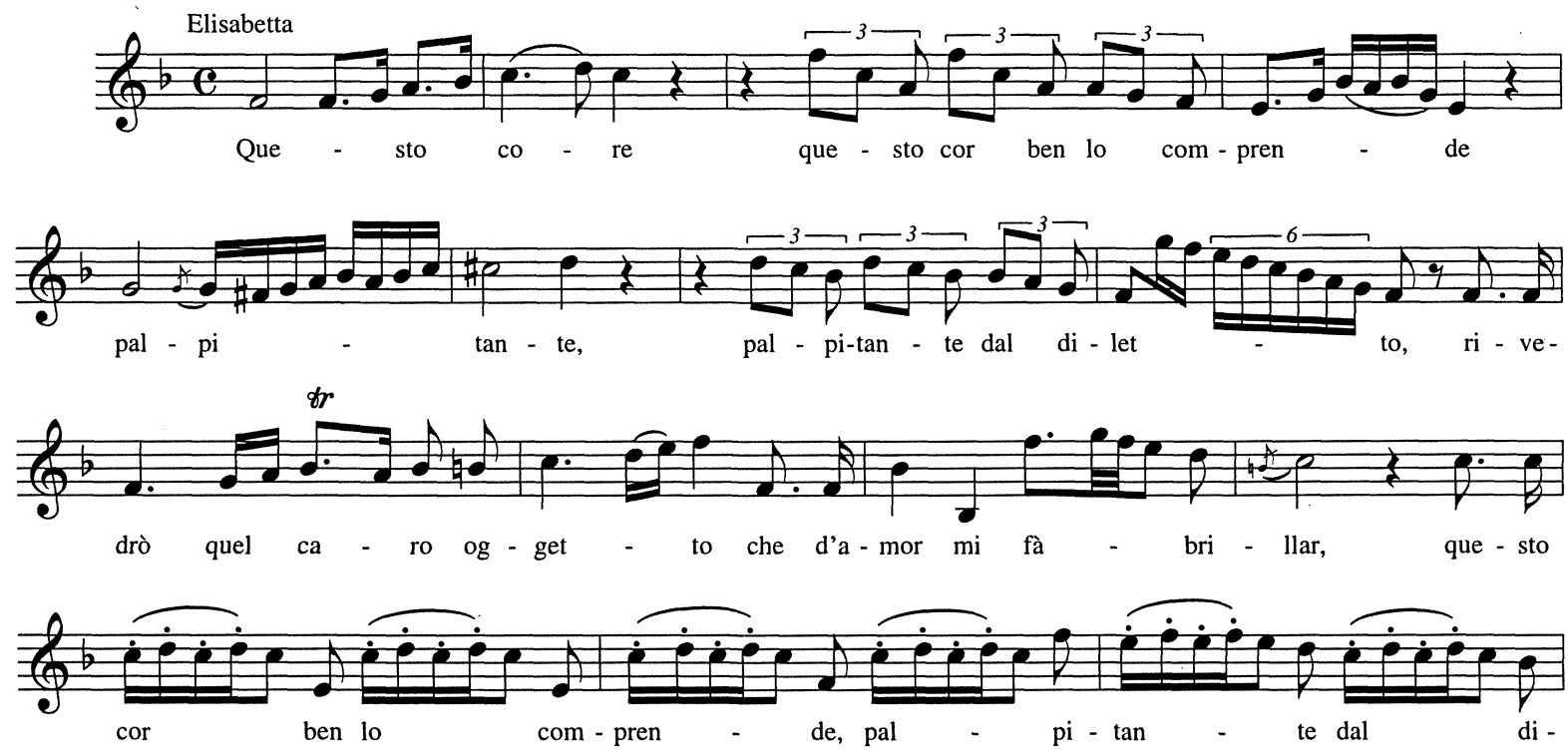


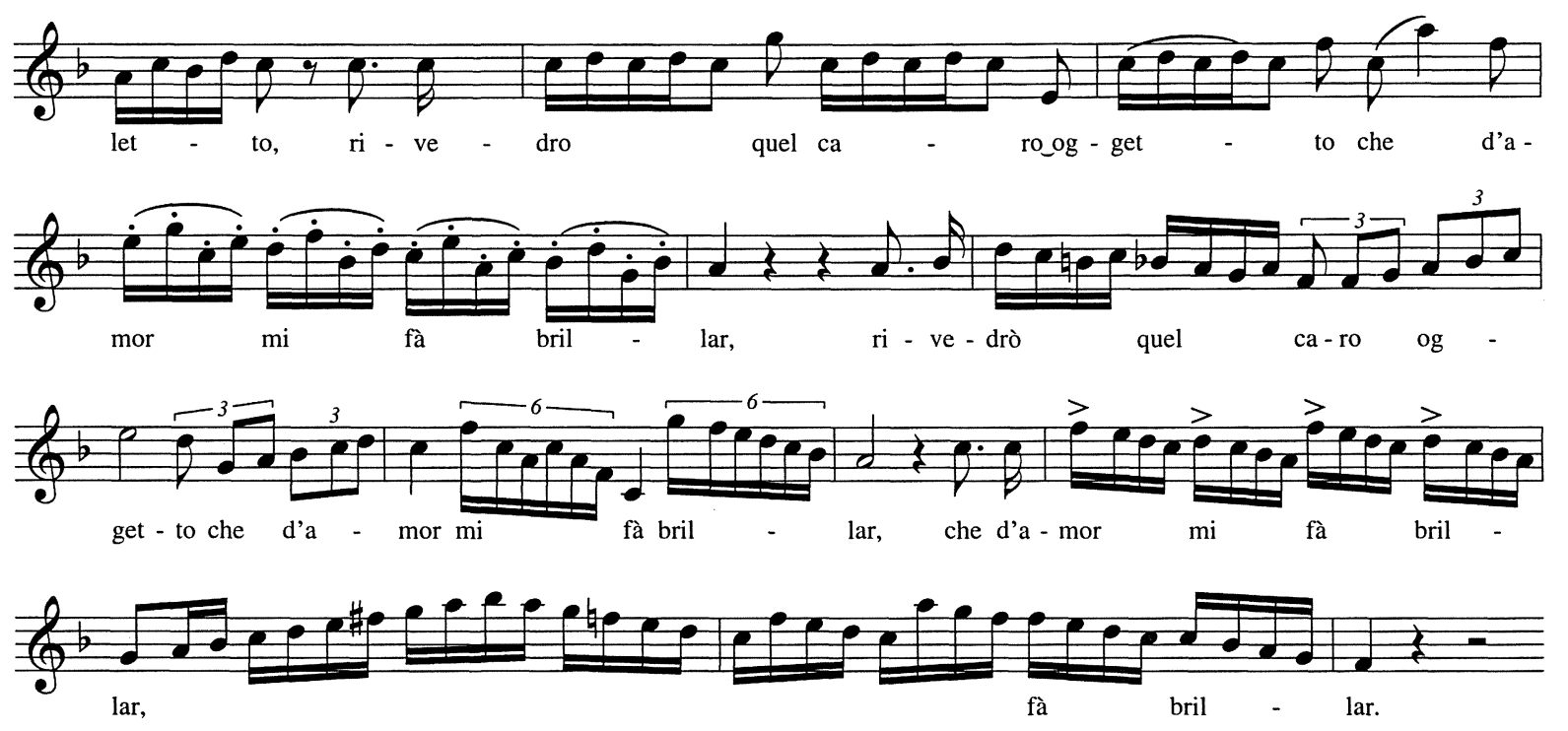

Ejemplo segundo:

\section{Il Barbiere di Siviglia}
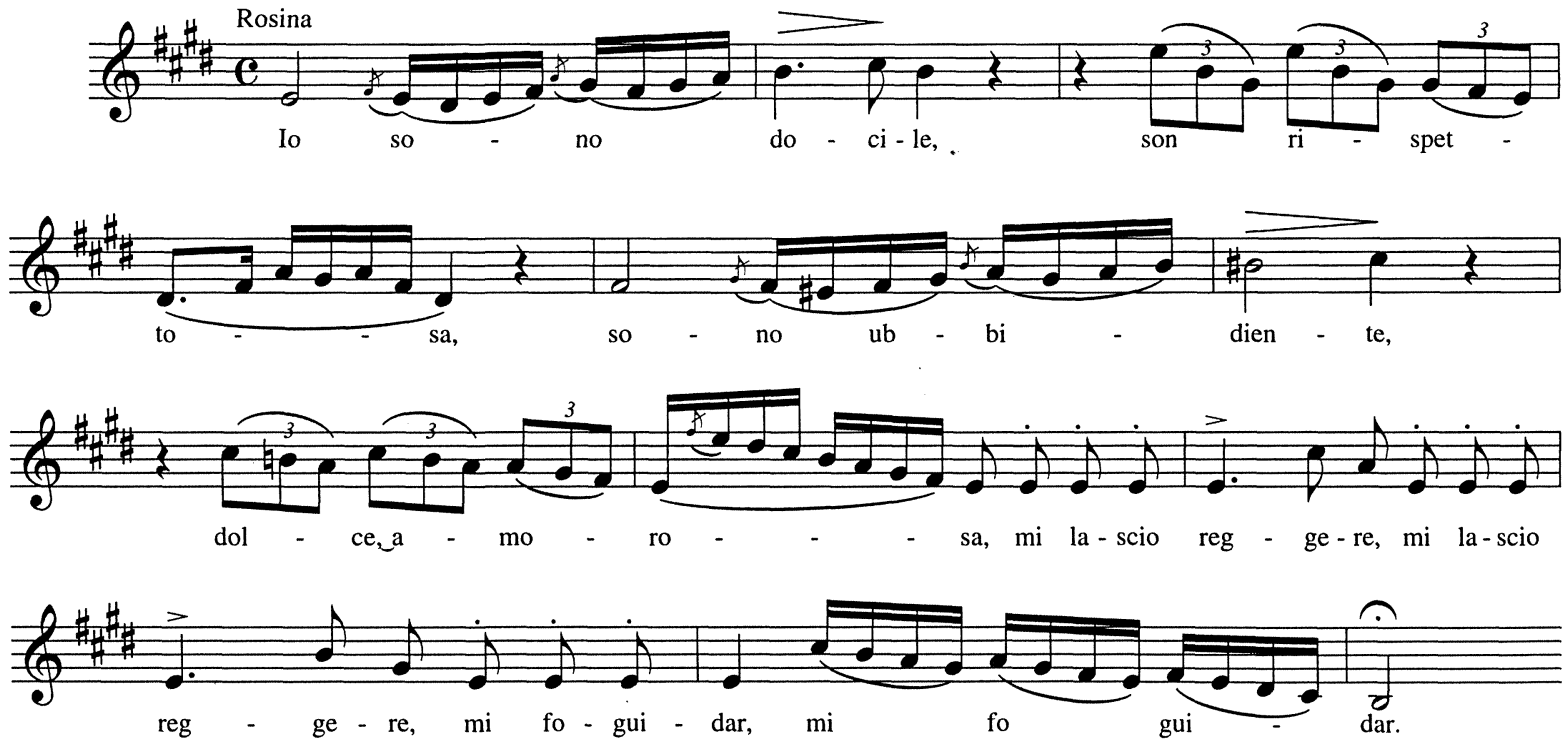

Anuario Musical, 55 (2000) 
Un ejemplo muy semejante se puede extraer de la comparación de otros dos fragmentos que parten de un tema musical común: La segunda sección del Rondó de Cenerentola en el final de la ópera escrita para Righetti Giorgi y la misma sección del aria de Cerere de Le nozze di Teti e Peleo que Rossini escribió algunos meses antes para Isabel Colbran con motivo de la celebración del enlace matrimonial de la princesa María Carolina y el Duque de Berry. También aquí la diferencia en la tesitura es evidente, Cenerentola canta dos tonos y medio por debajo de Cerere y en el desarrollo del tema Cenerentola (o sea la Righetti Giorgi) tenía que descender diversas veces hasta el sol\#2, mientras la Colbran alcanza sólo el sib2.

\section{Ejemplo tercero:}

\section{La Cenerentola}
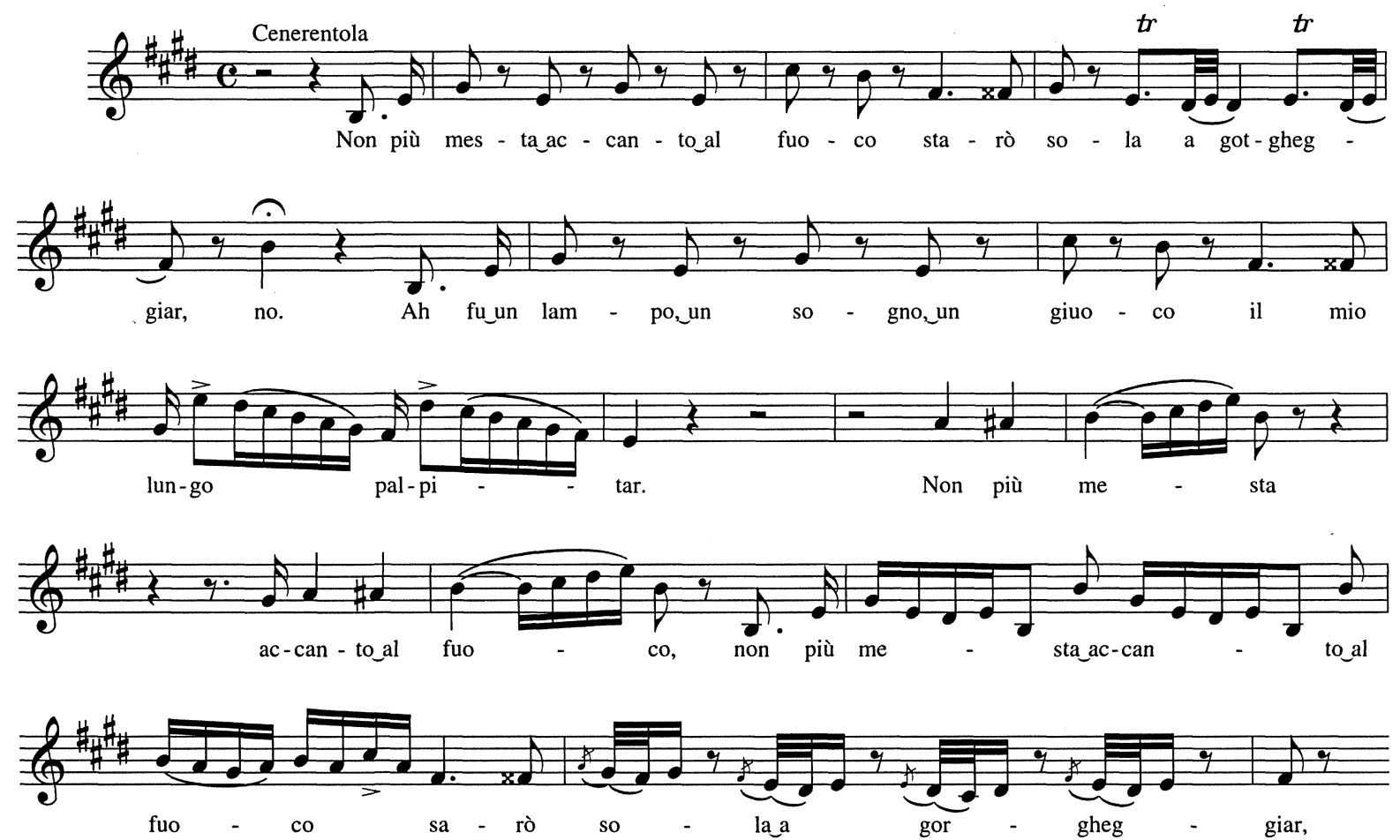
Ejemplo cuarto:

\section{Le Nozze di Teti e Peleo}
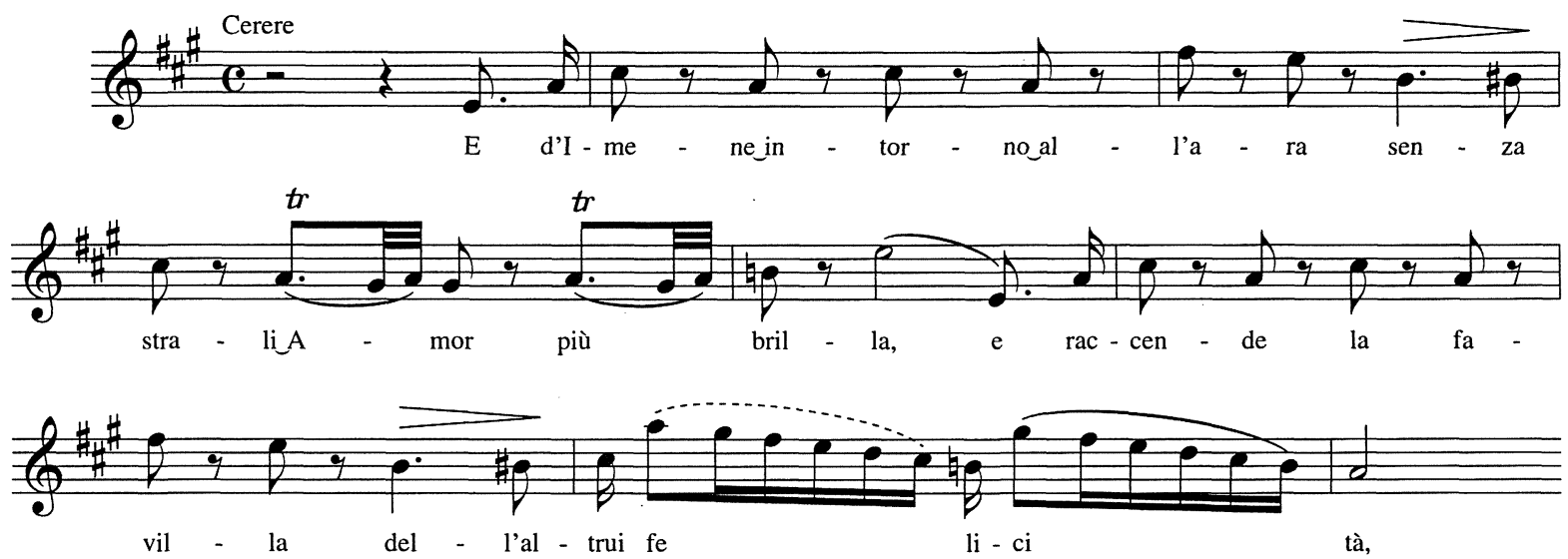

No ocurrió lo mismo cuando Rossini copió íntegramente el Rondó final de La donna del lago que había escrito para Colbran, para que lo interpretase una soprano, Violante Camporesi, en la escena final de Bianca e Falliero; aquí, aunque las diferencias en la instrumentación y el acompañamiento son notables, la línea melódica y la estructura armónica permanecen inalteradas.

La conclusión de todo ello es que Isabel Colbran fue una soprano central de registro agudo limitado, que en determinadas óperas presenta características que la aproximan a una mezzosoprano, pero que no la podemos considerar como tal ni por la extensión de la voz ni por las características dramatúrgicas de los papeles que interpretó. La teoría según la cual Isabel Colbran evolucionó de un repertorio de contralto a uno de soprano expuesta por Rodolfo Celletti ${ }^{92}$ debería excluirse, puesto que no parece que ella cantase notas muy graves en los inicios de su carrera ${ }^{93}$.

Quedaría siempre la duda de que, en el margen de improvisación que se le concedía al intérprete, añadiese notas más agudas a las escritas por el compositor, pero esto no es lo que se desprende de la edición de algunas arias en las que se incluyen las ornamentaciones introducidas por la Colbran. Tal es el caso, por ejemplo, del rondó de Portogallo "Per queste amare lagrime" en una edición publicada en Turín en los primeros años de su carrera ${ }^{94}$ en la cual Isabel Colbran

92. Celletti, Rodolfo: Storia del belcanto, La Nuova Italia Editrice, Firenze, 1996, p. 184.

93. En I-Mc no conserva la partitura de Coriolano, la primera ópera que cantó la Colbran, aunque en los tres fragmentos de esta ópera que editó Ricordi la extensión es muy limitada en lo que a graves se refiere (del re3 al si4). Lo mismo ocurre con el manuscrito de Ifigenia in Aulide de Federici, la segunda ópera que cantó, en la que la extensión es mi3-si4.

94. Per queste amare lagrime. Rondeau de Portugallo avec tous les agremens composés et chantés par la Celebre Mademoiselle Isabelle Colbran Membre de l'Accademie Philarmonique de Bologne pensionée de S.M. Catholique le Roi Joseph. Arrangè avec accompagnament de Forte Piano Par Monsieur Ottani Maître de la Chapelle de S.A.I. le Prince Cami- 
se mueve en una extensión muy central entre el fa3 y el si4. Lo mismo ocurre en otras dos arias en las que se recogen las variaciones realizadas por la Colbran: el aria "Ah che non serve il piangere" de la Alzira de Manfroce ${ }^{95}$, que ella estrenó en Roma en 1810 y en la cual las notas extremas son el re3 y el si4 y otra aria, "Ombra che a me d'intorno" de la Gabriella di Vergy de Carafa, estrenada por la Colbran en Nápoles, y de la que años después se publicó una edición en Londres. Aquí la extensión se mueve entre un do3 y un la $4^{96}$. Estas extensiones no dan demasiado crédito a la única crónica que menciona la extensión de la cantante, sobre todo en lo que a agudos se refiere ${ }^{97}$.

En estos documentos se aprecia además el gusto por el canto fiorito que distinguió el canto de la Colbran en el que coinciden tanto los testimonios de la época como el tipo de escritura que caracteriza a toda la música que Rossini escribió para ella. Un canto que Giuseppe Carpani definía así con motivo de la representación vienesa de Zelmira en 1822:

"La Signora Colbran ha un dolcissimo metallo di voce tonda e sonora massimamente nei tuoni di mezzo e ne'bassi. Un cantare finito, puro, insinuante. Non ha slanci di forza, ma bel portamento di voce, intonazione perfetta e scuola forbitissima. Le Grazie poi vanno spruzzando di nettare ogni sua sillaba, ogni suo fiore, ogni gruppetto. Ogni trillo. Cantante di primo rango la mostrano le volate di quasi due ottave per semituoni nette e perlate, e gli eletti artifizj del suo canto"98

Este uso -o abuso- del canto fiorito por parte de Isabel Colbran ha sido relacionado con algunos autores - Stendhal en primer lugar - como una muestra de la decadencia vocal de la cantante poco tiempo después de su encuentro con Rossini. Según Stendhal, la escritura vocal que caracteriza a los personajes rossinianos escritos para la Colbran es debida a la incapacidad de la cantante de sostener pasajes de canto spianato $^{99}$. Es posible que haya algo de cierto en estas consideraciones, puesto que en los inicios de la carrera de la cantante los testimonios indican que hacía uso de un canto spianato, sin adornos. En esta línea se expresó Giovanni Paisiello con motivo de la interpretación de Nina ossia la pazza del amore, con la que la cantante española debutó en Nápoles en 1811:

"Le confesso anzi sinceramente che io soffriva talvolta per lei nel sentirla cantare così ristrettamente come porta la musica, e senza permettersi la minima alterazione, mentre gli altri si abbandonavano con la loro arte ed aggiungevano giudiziosamente qualche adornamento, che può star bene

lle. A Turin Chez les Freres Reyend \& Comp. Libraires. La edición probablemente fue publicada en una de las dos temporadas que la Colbran pasó en Turín en 1811-1812 y 1812-1813.

95. "Ah che non serve il piangere", de Alzira de Nicola Manfroce. I-Rsc, A.Mss- 52.

96. Ombra che a me d'intorno The favorite Cavatina as Sung at Naples with Unbounded Applause by Madame Colbran in the Grand Serious Opera of Gabriella di Vergy composed by Signor D. Michele Carafa, arranged by Pio Cianchettini of London. London Printed \& Sold by Mr. Birchall \& C. 140, New Bond Street. La edición probablemente es de 1824, año en el matrimonio Rossini viajó a Inglaterra.

97. Il redattore del Reno, Bolonia, 21 de abril de 1807: "dal sol basso al mi sopracuto, cioè per quasi tre ottave".

98. Carpani, Giuseppe: Le rossiniane ossia lettere musico-teatrali, p. 158-159, Minerva, Padova, 1824.

99. Stendhal hace referencia frecuentemente a la Colbran en su famosa biografía de Rossini, aunque sus juicios han de ser muy relativizados, puesto que el escritor no tiene empacho en afirmar que asistió a representaciones a las que hoy sabemos que no asistió o en añadir anécdotas de difícil verificación. 
in essi, ma non nel carattere della Nina, che è il protagonista dell'opera. È vero che taluni potrebbero forse dire, che ella canti in quest'opera nella sua semplicità, la quale forma precisamente tutto il pregio di questo personaggio, non essendo altro che un parlante con una declamazione espressiva e animata, in somma come l'ha ella egregiamente eseguito. Ma costoro se mai vi fossero, non si saran data la pena d'internarsi nel vero senso della morte della Nina, la quale è una pazza per amore, ma non tale che abbia perduto il sentimento della sua passione, appunto come io l'ho immaginata."100

Lo mismo ocurre con las canciones que ella la misma compuso y en las que los pasajes de agilidad son limitados. Es posible que tanta ornamentación en las partituras rossinianas escondiese sus dificultades en el canto spianato, aunque también es sabido que en la carrera de Rossini en Italia se produjo una tendencia al enriquecimiento de las ornamentación escrita por el propio compositor, que encontró su punto culminante en Semiramide (1823), tendecia que dejaba menor espacio a la improvisación del intérprete ${ }^{101}$ y que puede conducir a la creencia errónea de que en partituras de otros compositores, la cantante no añadiese ornamentaciones por cuenta propia. De hecho, otra crónica publicada el mismo año en que cantó La Nina de Paisiello, hace referencia al abuso de la cantante con las ornamentaciones ${ }^{102}$.

En cualquier caso, entre las diversas variantes de "canto fiorito" que Manuel García hijo describió en su tratado de canto no hay duda que la que mejor se adapta al estilo de la Colbran es el "canto di bravura".

Tres de los ejemplos citados por García corresponden al repertorio que fue escrito para ella: el dúo de Elisabetta y Norfolk en Elisabetta, Regina d'Inghilterra, el aria de Desdemona al final del segundo acto de Otello y el trío de La donna del lago. Los tres fragmentos se sitúan en momentos particularmente vibrantes de la acción teatral, que son los más adecuados para desarrollar un canto di bravura. En este caso son el deseo de venganza de Elisabetta, el temor a la muerte de Otello en el caso de Desdemona seguido de un sentimiento de abandono de su padre y en el caso de La donna del lago, el amor no correspondido de Giacomo por Elena que continúa con la llegada de los soldados que Rodrigo reúne contra Giacomo y que son detenidos por Elena. En Elisabetta el tempo d'attacco presenta una agilidad en la que predominan notas acentuadas, que corresponden a las palabras "con qual fulmine improvviso", seguida de unos pasajes arpegiados en los que la cantante alcanza el sib4 y de numerosas notas en staccato. En este pasaje no faltan tampoco las apoyaturas, acciacaturas y un trino. Lo mismo ocurre en La donna del lago en donde nuevamente, en el tempo d'attacco, los arpegios son constantes entre Uberto y Elena, utilizando esta vez casi toda la extensión de la voz, que alcanza el si4 para descender hasta el do3. Las notas en staccato y los pasajes arpegiados reaparecen en el largo a solo de Desdemona "Che

100. Monitore delle due Sicilie, Nápoles, 14 de mayo de 1811.

101. Celletti, Rodolfo: op. cit. p. 168.

102. "La Signora Colbrand uso soverchiamente, e talvolta abusò della libertà che le veniva concessa dal compositore, dando alla sua voce un insolito e non sperato sviluppo, e caricando ogni nota di ornamenti stranieri più o meno felici. [...] in nessun momento fu ella tanto applaudita quanto in quello appunto in cui le pirouette sembravano gareggiare co'trilli e co'gorgheggi, con tanto maggiores impegno ed emulazione che, quelle nel ballo, questi nel canto, sono un abuso ed egualmente opposti a'veri principi dell'arte"Monitore delle due Sicilie, Nápoles, 19 de octubre de 1811. La referencia a "ornamenti stranieri" puede hacer pensar en algún tipo de ornamentación de orígen hispánico. 
smania ahimè”. No es de extrañar que sea casi siempre el tempo d'attacco el que presenta mejores ejemplos de canto di bravura puesto que como decía García: "Dopo un recitativo è di grande scuola l'attaccare un motivo con un passo di bravura" ${ }^{\text {"103 }}$. El cantabile con el que siguen, resulta más convencional, a veces muy breve, como en el Andantino, que sólo es un fase intermedia que desemboca nuevamente en un Allegro, en los que la cantante puede hacer nuevamente uso de todos sus recursos en el canto fiorito. Esto no quiere decir, naturalmente, que el "canto di bravura" fuese el único practicado por la Colbran. También uno de los ejemplos que García pone de otra variante del canto fiorito, el canto d'agilità corresponde con una ópera estrenada por la Colbran: el dúo "Amor, possente nome" de Armida, al cual se podrían añadir otros tantos de las óperas rossinianas como aquellas que estrenó de otros compositores. Queda todavía un último tipo de canto fiorito, que es el que García llama canto di maniera. No es este quizás el que se adapta mejor a las características del estilo de la Colbran, pero la referencia a una de las óperas rossianas que estrenó vuelve a ser ineludible; en este caso, se trata de la "Canzone del Salice", de Otello. También hace referencia en este apartado al aria que el maestro de Isabel, Gerolamo Crescentini, compuso, "Ombra adorata, aspetta," que la cantante incluyó en más de una ocasión en los conciertos de los inicios de su carrera. Una mirada sobre ambas partituras refleja efectivamente un uso del canto fiorito bastante diferente al de bravura. Sería difícil considerarlos pasajes puramente virtuosísticos porque requieren una interpretación delicada y expresiva que coincide plenamente con la definición de García. Este último aspecto de lo que era su estilo de canto, la aleja de cualquier suposición sobre lo que podría considerarse como un tipo de canto mecánico y puramente efectista. Así queda reflejado en la crónica del Giornale del Regno delle Due Sicilie sobre su interpretación en el estreno de Ricciardo e Zoraide:

L'inimitabile Signora Colbran, la quale aveva meritato finora i primi onori con singolare valore cantando di bravura, ha voluto farci questa volta conoscere essere in suo potere eccitare il maggiore entusiasmo piegando la sua bella voce ad un canto semplice ed espressivo il quale sembra averla renduta anche di più l'arbitra dei cuori ${ }^{104}$

En la misma línea se expresó el compositor Ludwig Spohr en su diario. Su visita a Nápoles coincidió con los dos conciertos que ofreció en el San Carlo Angelica Catalani, los cuales habían generado una enorme expectación en la ciudad. El primer concierto se celebró el 26 de marzo de 1817. Al día siguiente, la Colbran, que cantaba Elisabetta, Regina d'Inghilterra, fue abucheada por algunos partidarios de la Catalani. Spohr compara en su diario, Lebenserinnerungen, a ambas cantantes y el juicio que hace deja en buen lugar a la española, particularmente por la expresión de su canto:

"Sie steht der Catalani in Stimme und allem Mechanischen weit nach, singt aber mit wahrem Gefühl und spielt mit vieler Leidenschaft" ${ }^{105}$

103. García, M.: op. cit., p. 71.

104. Giornale del Regno delle Due Sicilie, Nápoles, 29 de diciembre de 1818.

105. Spohr, Ludwig: Lebenserinnerungen. Schneider, Tutzing, 1968. p. 24. 
La lectura de las partituras y los manuscritos lleva a hacer una reflexión sobre los criterios interpretativos de las óperas de los dos primeros decenios del siglo XIX, y en general, del repertorio operístico englobado bajo el término de bel canto.

No cabe duda de que el margen de improvisación del cantante de aquella época era muy superior al que se le concede al cantante de nuestros días interpretando el mismo repertorio. De hecho, esa improvisación era una parte integrante de la ópera misma, no sólo consentida, sino incluso, facilitada por el compositor. El estudio del estilo y de las formas de improvisación, su inserción en la ópera en los momentos pertinentes y de forma equilibrada, constituía una parte esencial del aprendizaje de un cantante ${ }^{106}$.

La capacidad para desenvolverse con holgura en los pasajes ornamentados, tanto si habían sido escritos por el compositor como si eran improvisados por el intérprete, merecía una valoración superior a otros aspectos puramente puntuales, como la exhibición, casi circense, de algunas notas sobreagudas que ha caracterizado la interpretación de algunas arias de este repertorio en interpretaciones posteriores.

El caso de la Colbran confirma una vez más, que el estilo belcantístico no tiene nada que ver con el exhibicionismo de notas sobreagudas. Ello no quiere decir, sin embargo, que una interpretación con criterios históricos de este repertorio, tenga que eliminar las variaciones y las ornamentaciones que los cantantes de la época añadían. La investigación musicológica debería favorecer una recuperación con criterios científicos y coherentes de estas variaciones y ornamentaciones, de las que se conserva mucha documentación, para enriquecer la interpretación de estas óperas, puesto que el artificio y la ornamentación vocal están de hecho en la base de la concepción dramatúrgica y musical de la ópera italiana que se engloba bajo el concepto de bel canto.

\section{Prima donna assoluta}

En el mundo de la ópera italiana del siglo XVIII y de principios del siglo XIX, el concepto de prima donna comportaba una serie de prerrogativas para la cantante que detentaba dicho título. Este es el título que acompaña a Isabel Colbran en los libretos del teatro San Carlo y en las crónicas de los periódicos de la época. Sin embargo, la proliferación del título de prima donna acompañando a diversas cantantes, obligó a usar un nuevo adjetivo que distinguiese entre el rango de las diversas prime donne que podía tener una compañía de ópera. Este adjetivo es asso-

106. Los tratados de canto del siglo XIX recogen ejemplos de formas tradicionales de ornamentación en las arias. El ya citado tratado de García recoge infinidad de ejemplos en este sentido. En él se pueden encontrar aseveraciones chocantes en nuestro tiempo, que ejemplifican muy bien los criterios interpretativos de la época. Sirva como ejemplo este pasaje referido a los recitativos: "Siccome in generale i recitativi non sono che una specie di luoghi comuni, l'artista è libero, senza offendere il compositore, di cangiarne la melodia; può permetterselo principalmente ogniqualvolta accada che la risoluzione dell' accordo imbarazzi la sua memoria. In tale circostanza, ei deve variare arditamente la cantilena, senza dipartirsi dal tono in cui canta e senza far sentire la $7^{\mathrm{a}}$ della dominante prima che sia resa dagli accompagnamenti. Allora risolverà la sua parte sulla $3^{\mathrm{a}}$ maggiore dell'accordo che presenta la risoluzione regolare." García, Manuel: Trattato completo dell'arte del canto, Ricordi, Milano, s.d. 
luta, título que aparece en el único contrato que se conserva entre Isabel Colbran y Domenico Barbaja, el empresario del teatro San Carlo firmado el 25 de febrero de 1817. La consideración como prima donna assoluta implicaba determinados derechos de la cantante, que, según Giovanni Valle, autor de un libro de costumbres jurídicas en el mundo de la ópera italiana, incluían la posibilidad de que la prima donna assoluta rechazase el libreto y la partitura de una ópera hasta que se hiciesen las modificaciones adecuadas en las que resultase evidente su condición de intérprete principal de dicha ópera ${ }^{107}$. En el caso de Isabel, estas prerrogativas figuraban también en el contrato firmado con Domenico Barbaja:

"La detta Sig. Artista si obbliga di eseguire le parti nella sua qualità di Prima donna assoluta nel modo in cui verrà distribuita dal Sig. Direttore, appartenendo ad essa pel bene dell'esecuzione ed interesse dell'Impresa il dirito di diminuire, di aumentare ed di levare a suo piacere i pezzi di musica e far eseguire i recitativi in prosa, secondo crederà conveniente, salva l'approvazione del Sig. Soprintendente"108

Dos ejemplos claros del intervencionismo de Isabel Colbran en la ejecución de una ópera, los tenemos en las representaciones de las dos únicas óperas de Mozart que Isabel cantó a lo largo de su carrera: Le nozze di Figaro, en el Teatro del Fondo de Nápoles, en marzo de 1814, interpretando el papel de la Condesa de Almaviva y Don Giovanni, en ese mismo teatro, en octubre de 1816, interpretando el papel de Donna Anna. El libreto de la representación de Le nozze di Figaro muestra claramente los cambios que se realizaron en estas representaciones para salvaguardar el carácter de prima donna assoluta de la Colbran. Susanna, papel que interpretaba Giacinta Canonici, no canta ninguna de sus dos arias, y Cherubino, papel que interpretaba la esposa de Manuel García, Joaquina García, no canta la primera de sus arias "Non so più cosa son" y cede a la Colbran la interpretación de la segunda "Voi che sapete", con un cambio en el recitativo que precede al aria que merece ser reproducido:

Susanna. Via presto la canzone, che stamane a me deste

A madama cantate.

La contessa. Chi n'è l'autor?

Sus. (alla Cont.)

Guardate, egli ha du braccia

di rossor sulla faccia.

La c. Prendi la mia chitarra, e l'accompagna.

Cher. Io sono si tremante...se madama

Degnasse di cantarla in vece mia...

Sus. (alla Cont.) Che ne dite? 1823 , p. 39.

107. Valle, Giovanni: Cenni teorico-pratici sulle aziende teatrali, Società Tipografica de' Classici italiani, Milano,

108. G. Rossini op. cit. pp. 201-203. 
La c. Lo voglio contentare

(a Cher.)

Sus. L'autore è di in buone mani, che te ne pare?

La c. Voi che sapete... ${ }^{109}$

Además de cantar este aria, Isabel Colbran interpretaba "Porgi amor" y sustituyó "Dove sono i bei momenti" por otra aria titulada "Sento mancarmi l'anima"110.

En el caso de Don Giovanni, actuó con un mayor respeto a la partitura y cantó las dos arias de Donna Anna sin realizar ningún cambio. Son los otros dos personajes femeninos, Zerlina y Donna Elvira, a los que les fue mutilada la parte: Donna Elvira no canta ninguna de sus dos arias, y a Zerlina le fue suprimida la segunda "Vedrai, carino"111. Estos cambios forman parte de la práctica teatral habitual en la época que permitía numerosos cambios a los cantantes principales en una ópera que no había sido escrita específicamente para ellos. Había dos motivos básicos para justificarlos: uno de tipo sociológico y otro musical e interpretativo. El primer motivo era la obligación de ajustar la partitura al rango de los diferentes intérpretes en la jerarquizada estructura de la compañía. A ojos del público, debía quedar claro cuál era la prima donna, la altra prima donna, la seconda donna, el primo tenore, etc. El motivo principal para realizar cambios desde un punto de vista musical era que las óperas tenían que acomodarse a las características de la compañía disponible y que por ello los papeles se tenían que ajustar a la tesitura adecuada para el cantante que interpretaba dicho rol, o bien transportando las arias o simplemente sustituyéndolas ${ }^{112}$.

Hasta el estreno de La donna del lago en 1819, Isabel Colbran no consintió que en el Teatro di San Carlo actuase otra prima donna con su mismo rango en la misma representación. Su sentido del rango era tal que consideraba incluso que el camerino que utilizaba estaba reservado para ella independientemente de que cantase o no esa ópera, lo cual fue motivo de algún conflicto ${ }^{113}$.

Los personajes psicológicamente fuertes son los que predominan en el repertorio que interpretó (Medea, Ermione, Semiramide, Armida, la reina Isabel de Inglaterra o Gabriella di Vergy).

109. Le nozze di Figaro, I-Bc, libretto $\mathrm{n}^{\circ} 3344$ p. 19.

110. Con toda probabilidad se trata del aria "Sento mancarmi l'anima", de Alonso e Cora de Mayr. En la copia conservada en B-Bc, 4413 el personaje que la interpreta es "La Contessa".

111. Don Giovanni, I-Bc, libretto ${ }^{\circ} 3356$.

112. "Quando la tessitura della musica d'una parte cantante non corrisponde alla di lei voce, per cui conviene o accomodarla se ne è suscettibile, o cambiarla senza eccezione, sostituendone altra che sia di gradimento all'attore stesso; quando quel tal pezzo di musica sia già stat sentito ed eseguito altre volte sull'istesso teatro da altri artisti che lo avessero per loro comodo inserito in diversi spartiti, e massime se questo successe poco tempo prima; - quando l'attore che deve eseguirlo sia invido al pubblico, o preso in aspetto burlesco, per cui non convenga avventurarlo in un pezzo sia isolato, sia concertato con altri, giacchè l'Impresa deve evitare tutto ciò che può nuocere tanto alla persona che al complesso degli attori" Valle, G.: op. cit. p. 91 .

113. Un informe de Giovanni Carafa, superintendente de Teatros y Espectáculos al Ministro de Interior se refiere a la reclamación de Margherita Chabrand, prima donna que participó en el estreno de La gazzetta de Rossini, porque no podía utilizar el camerino que habitualmente utilizaba la Colbran en el Teatro del Fondo puesto que ésta era la única en tener la llave del camerino. A la Chabrand se le ofreció el de las otras prime donne, pero ella como protesta, prefirió vestirse en el foyer. El informe de Carafa dejaba clara la actitud de la Colbran al respecto: "la quale pretende privatamente l'uso del suo camerino, perché a lei particolarmente assegnato, e come la sola prima donna addetta ai Reali Teatri" I-Nas. Min. Int. I Inv. f. 932. Publicado por Cagli B. y Ragni, S. op. cit. vol. I, p. 181. 
Fue con este tipo de personajes con los que alcanzó mayores éxitos y los que más veces representó. Sus apariciones en óperas semi-serias como Nina o la pazza per amore de Paisiello que tantos elogios mereció del propio compositor, eran ya consideradas por ella misma excepciones.

En la elección de la ópera seria como campo único de sus interpretaciones, se tiene que considerar, por una parte, su afinidad dramatúrgica hacia este tipo de roles, y por otra, la mayor consideración social que tradicionalmente ésta tenía, respecto a la ópera bufa. En esto, una vez más, la soprano madrileña se distancia de otras prime donne de su época que interpretaban alternativamente ópera seria y bufa como hicieron por ejemplo Teresa Belloc, o, posteriormente, María Malibran. Otra característica que diferencia su carrera de la de sus contemporáneas, es el mínimo interés que demostró por los papeles de primo uomo, papeles masculinos interpretados por una mujer. Únicamente hay registradas dos apariciones en este tipo de papeles, y en dos óperas que no fueron estrenadas por ella: el papel de Ariodante en Ginevra di Scozia, de Mayr (Teatro San Carlo, enero de 1815 y febrero de 1816) y Tancredi, de Rossini (Teatro San Carlo, agosto de 1815). En las decisiones que la vieron dedicada exclusivamente a cantar papeles de prima donna de ópera seria en teatros que siempre eran de primera fila, tenemos que interpretar una preocupación constante por salvaguardar su prestigio y por mantenerse en el nivel más alto de la jerarquía teatral.

En el plano puramente artístico se ha hecho mención en más de una ocasión a la influencia que Isabel tuvo en el cambio de dirección de la carrera de Rossini, que a partir de 1817, después del estreno de La cenerentola, abandonó la ópera bufa, cambio que coincide cronológicamente con las fechas en las que aproximadamente se inició la relación entre ambos. En la época de Rossini, un compositor no podía conformarse con componer óperas de tipo bufo porque el teatro más importante de una ciudad, como era el caso del San Carlo, se dedicaba únicamente a la ópera seria, mientras las óperas bufas se reservaban para otros teatros como el Fondo, el Nuovo o el dei Fiorentini. Cualquier compositor de ópera italiana se veía obligado a componer ópera seria si realmente aspiraba a alcanzar un sólido prestigio. Rossini ya había estrenado varias óperas serias antes de iniciar su colaboración artística con Isabel Colbran. Lo que verdaderamente sorprende no es que escribiese óperas serias, sino que abandonase radicalmente la composición de óperas bufas y en ello sí que es muy posible que haya tenido una gran influencia Isabel Colbran, cuya naturaleza artística no era nada afín a lo bufo y que pudo contribuir a concentrar los intereses artísticos de Rossini en la ópera seria. No hay duda de que el período 1815-1823, desde su llegada a Nápoles hasta la composición de la última ópera estrenada en Italia, marca un ciclo en la carrera rossiniana, ciclo en el que las características asociadas al canto rossiniano encontraron su plasmación más vibrante y del que fue protagonista principal Isabel Colbran.

\section{Isabel Colbran, compositora}

La composición de canciones era una actividad habitual de muchos cantantes del siglo XIX. Algunos, como el famoso tenor Manuel García nos legaron además tonadillas, óperas y can- 
tatas, entre las cuales se encuentran Il califfo di Bagdad (1813), La donzella di Raab (1814) y la cantata Diana ed Endimione (1814), que la misma Colbran estrenó en el Teatro San Carlo de Nápoles. Muchas prime donne, aunque no alcanzaron los niveles de profesionalidad del tenor sevillano, escribieron composiciones, destinadas en la mayoría de los casos a ser interpretadas por ellas mismas. Sin salir del ámbito rossiniano, podemos citar los nombres de María Malibran, Caroline Ungher, Giuditta Pasta, Josephine Fodor Mainvielle, Angelica Catalani o Pauline Viardot. Dentro de este grupo, tanto por la calidad como por el número de composiciones el caso de Isabel Colbran alcanza un particular interés.

Casi todas las composiciones de Isabel Colbran pertenecen al primer período de su carrera, los años comprendidos entre 1805 y 1809, y pueden ser consideradas como un elemento de propaganda en los primeros años de su carrera.

Su obra musical hasta ahora conocida, está constituida por cuatro álbumes de canciones con seis canciones cada uno, además de dos canciones sueltas, y una pequeña cantata con acompañamiento de piano que compuso en homenaje a su padre.

El primer álbum está dedicado a la reina María Luisa de Parma en agradecimiento a la pensión que ésta le concedió para que completase sus estudios en el extranjero ${ }^{114}$. Este álbum fue publicado en 1805 en París "au Magasin de Musique dirigé par Mms Cherubini, Méhul, Kreutzer, Rode, Isouard y Boildieu”. Un segundo álbum, fue publicado en 1808, coincidiendo con el retorno de Isabel a París. El álbum fue dedicado a "Sa Majesté l'Impératrice de toutes les Russies", Isabel de Baden, personaje que resulta difícil relacionar con la soprano española, aunque no podemos excluir que en algún momento la cantante haya tenido en perspectiva un contrato en San Petersburgo $^{115}$. El agradecimiento a María Luisa de Parma, no le impidió dedicar otro álbum de canciones a la nueva reina de España, Marie Julie, esposa de José I Bonaparte, a la que pudo conocer durante esa segunda estancia en París, cuando fue nombrada cantante de cámara de José I en 1808. El último álbum está dedicado a su maestro Gerolamo Crescentini, con el que se reencontró en París en $1808^{116}$ y algunos años después en Nápoles. Si los tres anteriores están publicados por el mismo editor, este último fue publicado por Montmigny. Se tiene noticia de un quinto álbum dedicado al virrey de Italia, Eugenio Beauharnais, al que se refiere una nota de Il Giornale el Campidoglio de Roma del 29 de septiembre de 1810, pero del cual no tenemos en realidad ninguna certeza de que fuese realmente publicado. Sorprendentemente, la mayor parte de las notas biográficas en los diccionarios citan este último álbum, pero casi ninguna menciona el dedicado a Marie Julie.

114. Señora

Ni el cumplimiento de mi obligación, ni la debida gratitud á tanta gracia recibida de la piedad de V.M. me hubieran animado á poner su augusto nombre al frente de unas canciones, que acabo de componer. La indulgencia de V.M. vence unicamente mi justa timidez. He cedido à la porfia de los primeros Profesores de Musica de este pais, que han deseado cantase alguna cosa mia. Como las primicias de mi corto talento aunque no dignas de V.M. la pertenecen, mi humildad guiada por la justicia las consagra.

115. Es curioso señalar que la última de las canciones del segundo álbum "Mi lagnerò tacendo" está basada en un texto de Metastasio que Rossini musicó años después en repetidas ocasiones. Lo mismo ocurre con el texto de "Già la notte s'avvicina", también de Metastasio, que Rossini musicó con el título "La pesca" en las Soirées Musicales publicada en 1835. De cualquier forma, es difícil valorar aquí algun tipo de influencia de la Colbran, puesto que se trata de textos que fueron también utilizados por muchos otros compositores.

116. Una noticia de la publicación de este álbum se encuentra en La Gazette Nationale ou Le Moniteur Universel, París, 27 de junio de 1808. 
En 1808, poco antes de dejar París, Isabel escribió la Cavatina o canzonetta di partenza o ultimo addio, dedicada a Marinelli, a Crescentini y a todos sus amigos de París. En 1825, cuando ya hacía tres años que había dejado de cantar en el Teatro San Carlo de Nápoles, el editor Girard publicó en los Passatempi Musicali una barcarola titulada "Già la notte s'avvicina". Mucho más difícil es datar la pieza de ocasión que Isabel escribió para el cumpleaños de su padre, y que en cualquier caso es anterior a 1820, año del fallecimiento de Juan Colbran. La cantata, que lleva por título Del giorno natalizio di Giovanni Colbrand la figlia riconoscente, y que es un manuscrito atribuible a todas luces a la misma mano de Isabel, es el único documento que conocemos en que padre o hija escribiesen su apellido con la "d" final que tan frecuentemente aparece en algunos artículos periódisticos y en algunos libros de la época, entre ellos la famosa Vie de Rossini de Stendhal.

Joaquín Espín y Guillén, familiar de la cantante, afirmaba poseer un "ária á grande orquesta de esta célebre española instrumentada con esmero y conocimiento: el canto pertenece á la lujosa escuela de vocalización de la autora" ${ }^{117}$, de la cual, no se tienen otras noticias. No se tiene tampoco constancia del estreno de ninguna de sus obras, aunque es factible imaginar que, por la misma naturaleza de las canciones, fuesen estrenadas por ella misma en conciertos de carácter privado.

Pocos elementos de estas composiciones pueden delatar el origen español de la compositora. En esto sus obras se diferencian netamente de las de Manuel García. Son canciones escritas en italiano, aunque los tres primeros álbumes están también traducidos al francés. En todos los aspectos, empezando por el literario, la compositora se ajusta perfectamente al modelo ideal de arietta de cámara italiana. Los textos - la mayor parte de los cuales pertenecen a arias de óperas de libretos de Metastasio-, forman estructuras de cinco o seis, como máximo ocho versos pentasílabos, hexasílabos o octosílabos, que en algún caso llegan a decasílabos ${ }^{118}$. Desde el punto de vista armónico apenas presentan rasgos significativos, con pasajes de modulación muy sencillos. Extremadamente sencillos en las primeras canciones - las dedicadas a la reina María Luisa- en las que usa frecuentemente un calderón para pasar de la modulación a la tonalidad principal y ligeramente más complejos en álbumes posteriores, en las que usa ya un ritornello como ocurre en la segunda canción del álbum dedicado a Marie Julie. También en este álbum como en el que poco después dedicó a Crescentini, enriquece las composiciones con un mayor número de signos expresivos. La línea vocal en todas las canciones es relativamente sencilla en comparación con la gran cantidad de ornamentaciones que caracterizan las arias que Rossini escribiera después para ella. Son frecuentes las apoyaturas y las acciacaturas. En los dos últimos álbumes aparecen con más frecuencia algunos arpegios rápidos, aunque siempre de forma limitada. Las tesituras son muy centrales, entre un mi3 y un la4 y permiten ser interpretadas indistintamente por una soprano o una mezzosoprano. El acompañamiento de los cuatros álbumes, que prevé normal-

117. Gaceta de Madrid, 25 de febrero de 1857, publicado por Saldoni, B.: op. cit. I, p. 216.

118. Las únicas canciones con versos decasílabos son la cuarta pieza del álbum dedicada a la Emperatriz de Todas las Rusias, "Ch'io mai vi possa lasciar d'amare", y la quinta "Se son lontano dal mio diletto", y la sexta "Quel ruscelletto che l'onde chiare" del álbum dedicado Marie Julie. 
mente arpegios para la mano de derecha y sencillos acordes para la izquierda, está previsto para piano o arpa, indistintamente.

Una canción que puede servir de ejemplo de las características hasta aquí expuestas es "Ombre amene amiche", la primera canción del álbum dedicado a Marie Julie, escrita en tonalidad de fa menor. Desde un punto de vista armónico, esta pieza presenta una alternancia de tonalidades mayores y menores. Los primeros quince compases están en fa menor hasta que el calderón del compás 16 nos sitúa en tonalidad de fa mayor. A partir de ese momento empieza una segunda sección, marcada también por cambio en el tiempo, de "Andantino" a "Allegretto", en la que la linea melódica se mueve en una alternancia de terceras a tonalidades de paso como la bemol mayor, re bemol mayor, para volver de nuevo a fa mayor. En la linea vocal se encuentran alguna ornamentaciones esporádicas a las que hay que añadir las que la cantante improvisaba sobre los "a piacere" que figuran en los compases 15 y 52 . La nota más aguda es un la4 que se encuentra en los compases finales, al inicio de una escela descendente. El acompañamiento se limita a presentar arpegios de semicorcheas en la primera sección y acordes que se alternan entre la mano derecha y la izquierda en la segunda. La canción presenta pocos signos expresivos, que debían ser confiados también a la propia improvisación de la cantante.

La Cavatina o canzonetta Di partenza o ultimo addio y la Barcarola tienen características muy similares a las composiciones recogidas en los cuatro álbumes mencionados. Incluso la cantata manuscrita dedicada a su padre con motivo del día de su aniversario está escrita en italiano ${ }^{119}$. El texto, escrito con toda probabilidad por la misma Isabel, es un testimonio más del afecto que unía a la hija con su padre.

La cantata, escrita en tonalidad de do mayor resulta un tanto decepcionante. Una larga introducción crescendo del piano de veinticuatro compases en la que abundan los trinos, precede a la exposición del tema, que en la primera parte no presenta demasiadas ornamentaciones y que en una segunda parte resulta más rica en lo que se refiere a la agilidad. El acompañamiento es sencillísimo, y la composición en conjunto, tiene sólo un valor circunstancial y anecdótico.

Al igual que Isabel Colbran dedicó la mayor parte de sus composiciones, también algunos compositores le dedicaron algunas obras. Uno de estos compositores fue Alexis de Garaudé (1779-1852) que le dedicó su Sexième Recueil de Romances avec accompagnament de piano forte con texto y música del compositor. Romanzas que llevan por título Clara: romance a trois notes, L'amour au village y La constance. Otro compositor, Abraham Louis de Niedermayer (1802-1861) le dedicó unas Variations: pour le pianoforte sur la cavatina Oh mattutini albori, introduction de l'opera La donna del lago de Rossini. También el compositor valenciano José Melchor Gomis, que buscaba en París en 1826 la recomendación de Gioachino Rossini e Isabel, le dedicó una Canción española ${ }^{120}$.

119. El manuscrito de la cantata forma parte del Fonds Michotte, B-Bc.

120. Gisbert, Rafael: Gomis, un músico romántico y su tiempo. Ajuntament d'Ontinyent, Ontinyent, 1988. Una edición de la canción se encuentra en F-Pn. Département de la Musique: Vm7, 60423 "Canción española". 


$$
Y^{0} 1
$$

Andantino.
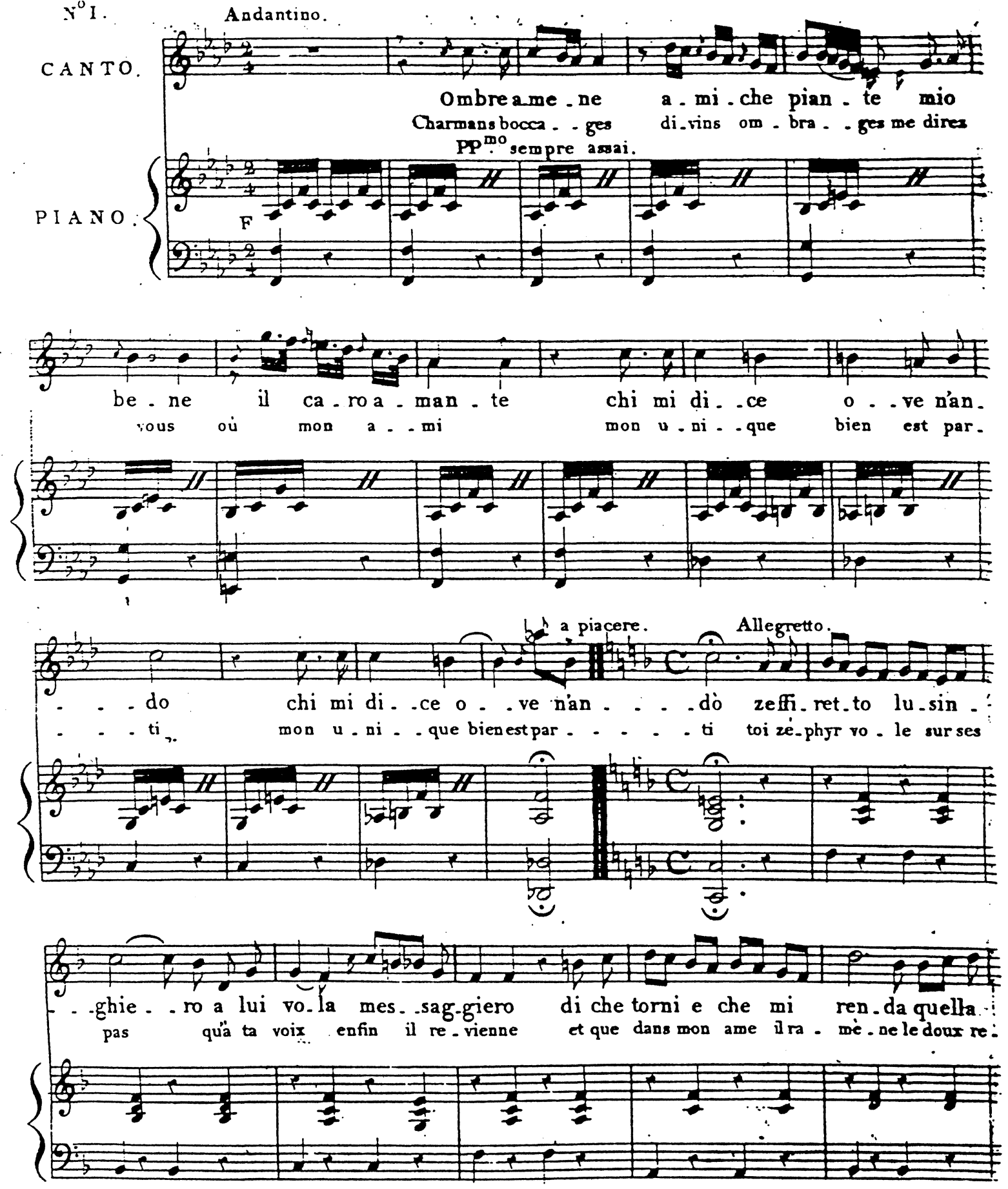

“Ombre amene amiche”, del álbum dedicado a Marie Julie, París, 1808 

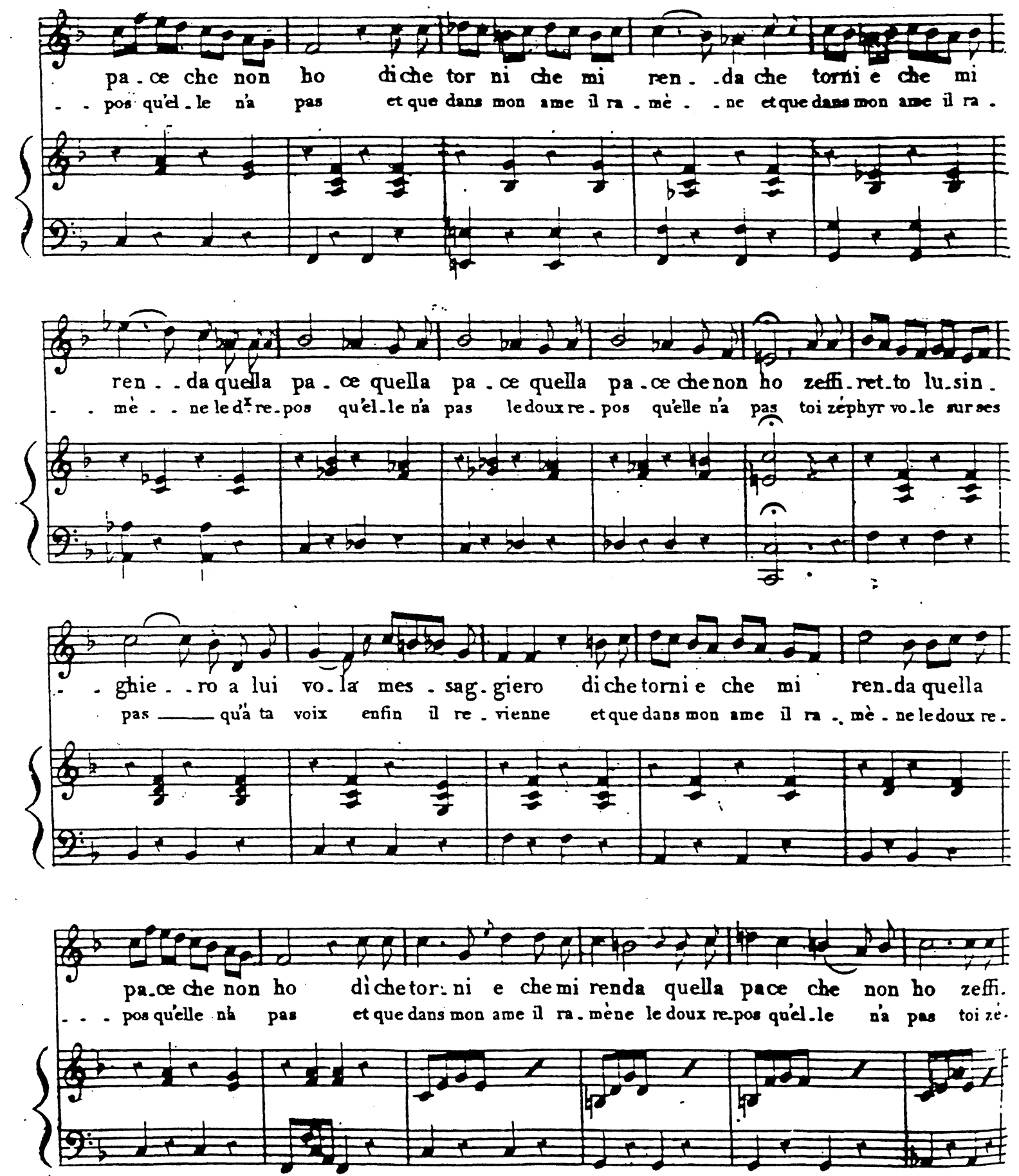

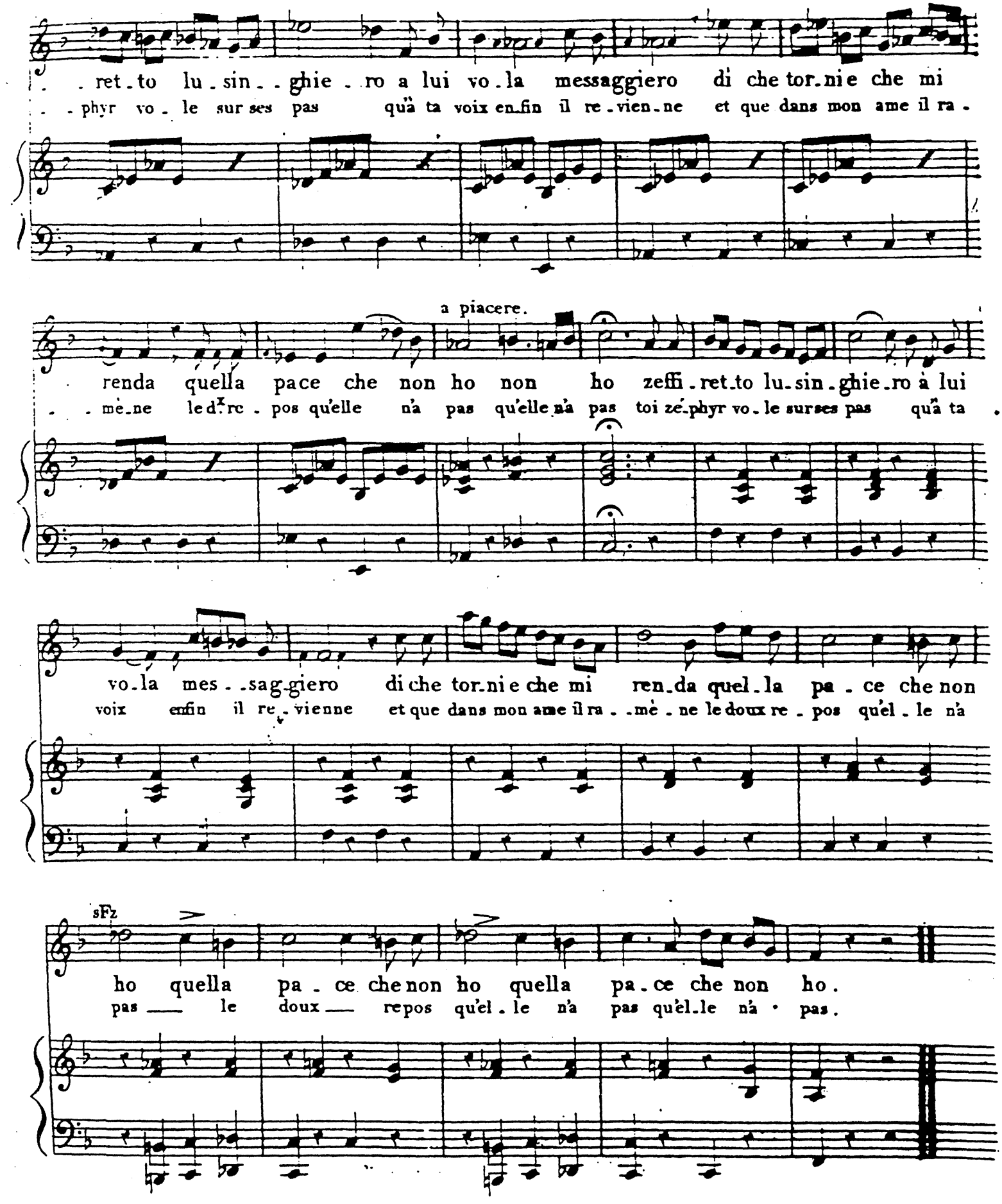


\section{Conclusión}

Aunque la fortuna artística de algunas de las herederas de Isabel Colbran, como Giuditta Pasta, María Malibran o Erminia Frezzolini, ha ensombrecido parcialmente la carrera de la soprano madrileña, una visión global de su trayectoria artística no deja lugar a dudas sobre el papel principal que esta cantante tuvo entre las cantantes de su época. Pocas contemporáneas la igualaron en fama, aunque la relación artística entre Isabel Colbran y Rossini, ponen a la española en el centro de atención de una mirada retrospectiva hacia aquella época. Más allá de las afinidades personales entre ambos, en su relación aparece una evidente afinidad artística. Ambos parecen encarnar un último episodio de una concepción del canto heredera todavía de los presupuestos del estilo de canto del Setecientos, en los que la ornamentación vocal se concibe como el fruto de un arte ideal alejado de cualquier tipo de realismo. No hay duda de que "se Rossini era davvero, come amava definirsi l'ultimo dei classici, la Colbran impersonava anch'essa l'estremo lembo belcantistico de la classicità"121.

El estudio de la ópera italiana de los siglos XVIII y XIX sin tomar en consideración las características y la trayectoria artística de los cantantes que fueron protagonistas del estreno de aquellas óperas, será siempre parcial, puesto que en pocos casos como en este, la influencia del intérprete es tan determinante. Su personalidad se encuentra muchas veces en la base de las motivaciones artísticas del compositor y su protagonismo en la compleja trama de creación de una obra merece una consideracion mucho más allá de la puramente anecdótica. Una aproximación a su trayectoria y personalidad artística puede contribuir también a afrontar la interpretación de las óperas con criterios históricos, criterios de los cuales no puede ser excluída la voz, que en el caso de la ópera italiana, no en vano conocida como belcantista, constituye el medio expresivo por excelencia del compositor. En este contexto, no resultará inútil aproximarse a la figura de la española Isabel Colbran, la soprano rossiniana por antonomasia.

\section{Anexo}

Las fuentes esenciales para aproximarse la biografía de Isabel Colbran, y de las cuales parten la práctica totalidad de los datos biográficos recogidos en las enciplopedias, son los datos del artículo escrito por Joaquín Espín y Guillén en la Gaceta de Madrid del 25 de febrero de 1857 publicado por Baltasar Saldoni en el Diccionario biográfico-bibliográfico de Efemérides de Músicos Españoles, Madrid, 1868-1881. Reprod. fac. Centro de Domumentación Musical, Madrid, 1986; los juicios de Giuseppe Carpani en Le Rossiniane, Minerva, Padua, 1824, el artículo que le dedicó Fétis en la Biographie universelle des musiciens et bibliographie générale de

121. Mioli, Piero: "Fu vera gloria. Osservazioni sull'arte vocale d'Isabella Colbran" en Rossini: Tutti i libretti d'opera vol. 1, p. 389, Roma, 1997. Articulo publicado anteriormente en Studi in onore di G. Vecchi, dirigido por I. Cavallini, Modena, 1989. 
la musique, Firmin Didot Frères, París, 1866-1870 y las no demasiado fiables opiniones de Stendhal en su famosa biografía que dedicó a Rossini, de la cual existe traducción al castellano Vida de Rossini, trad. de Consuelo Berges, Aguilar, Madrid, 1987. Enriquecieron sensiblemente el panorama los datos aportados por la monumental biografía de Rossini de Giuseppe Radicciotti, Gioacchino Rossini, Vita documentata, opere ed influenza su l'arte, Tivoli, Arti Grafiche Majella, 1927-1929, de la que son deudoras las biografías de Herbert Weinstock Rossini: a biography, Knof, Nueva York, 1968, Richard Osborne: Rossini, Dent, Londres, 1986 y Frédéric Vitoux: Gioacchino Rossini, Mazarine, París, 1982.

Un artículo enciclopédico interesante y que me sirvió como punto de partida es el que escribió Ariella Lanfranchi en el Dizionario degli Italiani, Instituto della Enciclopedia Italiana, Roma, 1982. Los artículos publicados en el New Grove Opera por Elisabeth Forbes y por $\mathbf{M}^{\mathbf{a}}$ Encina Cortizo en el New Grove Dictionary of Women Composers, no aportan datos significativos. Mucho más completo es el artículo recientemente publicado por ésta última en el Diccionario de la Música Española e Hispanoamericana, SGAE, Madrid, 1999 en el que se perpetúan algunos errores, pero donde se realiza una muy buena síntesis de la trayectoria de la cantante.

Los dos volúmenes publicados por Bruno Cagli y Sergio Ragni Gioachino Rossini: Lettere e documenti, Pesaro, 1992, 2 vols. (a los que en breve se añadirá un tercero) publican documentos referidos a Rossini, pero también a Isabel Colbran. Sus riquísimas notas son la fuente reciente más precisa para obtener datos documentados de la biografía ambos. El mismo Sergio Ragni ha publicado dos artículos biográficos, el primero en la revista de divulgación Scherzo, $\mathrm{n}^{\circ}$ 86, Madrid, 1994 (que dedicó a la soprano española un dossier monográfico coordinado por Víctor Pagán, que incluía también una cronología realizada por Luigi Cuoco), y el segundo, "Isabella Colbran: Appunti per una biografía” en el Bolletino del Centro Rossiniano di Studi, Pesaro, 1998.

Muchos datos sobre los cantantes rossinianos, en general, y la Colbran en particular se encuentran en la monografía de Giorgio Appolonia: Le voci di Rossini, Turín, Eda, 1992. La tesis doctoral de James Radomski The life and works of Manuel del Populo Vicente García: Italian, French and Spanisch Opera in Early Nineteenth-Century Romanticism, University of California, Los Angeles, 1992 aporta también algunos datos interesantes sobre la biografía de la cantante. Aunque no aporta datos concretos sobre Isabel Colbran, el ambiente del teatro musical italiano del siglo XIX ha sido estudiado por John Rosselli The opera industry in Italy from Cimarosa to Verdi, Cambridge University Press, Cambridge, 1984 y Singers of Italian Opera, Cambridge University Press, 1992.

Una aproximación a la vocalidad de esta cantante la realizó Piero Mioli en el artículo "Fu vera gloria: Osservazioni sull'arte vocale d'Isabella Colbran-Rossini”, Studi in onore di G. Vecchi, a cargo de I. Cavallini, Modena, Mucchi, 1989. También Giorgio Appolonia publicó un artículo de carácter divulgativo en "La cantante en sus partituras", Scherzo, n 86, Madrid, 1994. Aunque la obra de Rossini ha sido objeto de numerosos estudios musicológicos, estos obvian en muchas ocasiones el problema de la vocalidad. Muy interesante es la aportación de la tesis del Marco Beghelli I trattati di canto italiani dell'Ottocento, Università di Bologna, 1995. No pueden ser obviadas las opiniones de Michael Aspinall en el artículo "Il cantante nelle interpreta- 
zioni delle opere rossiniane”, Bolletino del Centro Rossiniano di Studi, n. ${ }^{\circ}$ 1, Pesaro, 1970 y la visión sobre la vocalidad rossiniana de Rodolfo Celletti, "Origini e sviluppi della coloratura rossiniana" Rivista musicale italiana, n 5, ERI, Turín, 1970 y en su Storia del belcanto, La Nuova Italia Editrice, Florencia, 1996. Imprescindibles, los datos aportados en las ediciones críticas de las partituras rossinianas publicadas por la Fondazione Rossini de Pesaro. Otras fuentes, demasiadas para mencionarlas en esta nota, aportan detalles que enriquecen el conocimiento de la trayectoria de esta cantante. 